Cochrane Database of Systematic Reviews

\title{
Enamel etching for bonding fixed orthodontic braces (Review)
}

Hu H, Li C, Li F, Chen J, Sun J, Zou S, Sandham A, Xu Q, Riley P, Ye Q

Hu H, Li C, Li F, Chen J, Sun J, Zou S, Sandham A, Xu Q, Riley P, Ye Q.

Enamel etching for bonding fixed orthodontic braces.

Cochrane Database of Systematic Reviews 2013, Issue 11. Art. No.: CD005516.

DOI: 10.1002/14651858.CD005516.pub2.

www.cochranelibrary.com 
TABLE OF CONTENTS

ABSTRACT 1

PLAIN LANGUAGE SUMMARY

SUMMARY OF FINDINGS

BACKGROUND

OBJECTIVES

METHODS

Figure 1.

RESULTS

Figure 2.

DISCUSSION

AUTHORS' CONCLUSIONS

ACKNOWLEDGEMENTS

REFERENCES

CHARACTERISTICS OF STUDIES

DATA AND ANALYSES

Analysis 1.1. Comparison 1 Self etching primers versus conventional etchants, Outcome 1 Bond failure rate (5 to 37 months). .. 38 ADDITIONAL TABLES

APPENDICES

WHAT'S NEW

HISTORY

CONTRIBUTIONS OF AUTHORS

DECLARATIONS OF INTEREST

SOURCES OF SUPPORT

DIFFERENCES BETWEEN PROTOCOL AND REVIEW

NOTES

INDEX TERMS 
[Intervention Review]

\section{Enamel etching for bonding fixed orthodontic braces}

Haikun Hu${ }^{1}$, Chunjie Li², Fan Li ${ }^{1}$, Jianwei Chen ${ }^{1}$, Jianfeng Sun ${ }^{1}$, Shujuan Zou ${ }^{1}$, Andrew Sandham ${ }^{3}$, Qiang Xu3 ${ }^{3}$, Philip Riley ${ }^{4}$, Qingsong Ye1,3,5

1Department of Orthodontics, State Key Laboratory of Oral Diseases, West China College of Stomatology, Sichuan University, Chengdu, China. 2Department of Head and Neck Oncology, State Key Laboratory of Oral Diseases, West China Hospital of Stomatology, Sichuan University, Chengdu, China. ${ }^{3}$ Department of Orthodontics, School of Medicine and Dentistry, James Cook University, Cairns, Australia. ${ }^{4}$ Cochrane Oral Health, Division of Dentistry, School of Medical Sciences, Faculty of Biology, Medicine and Health, The University of Manchester, Manchester, UK. 5 School of Stomatology, Wenzhou Medical University, Wenzhou, China

Contact: Qingsong Ye, Department of Orthodontics, School of Medicine and Dentistry, James Cook University, Cairns, Australia. qingsongye@hotmail.com.

Editorial group: Cochrane Oral Health Group.

Publication status and date: Stable (no update expected for reasons given in 'What's new'), published in Issue 5, 2018.

Citation: Hu H, Li C, Li F, Chen J, Sun J, Zou S, Sandham A, Xu Q, Riley P, Ye Q. Enamel etching for bonding fixed orthodontic braces. Cochrane Database of Systematic Reviews 2013, Issue 11. Art. No.: CD005516. DOI: 10.1002/14651858.CD005516.pub2.

Copyright ( 2018 The Cochrane Collaboration. Published by John Wiley \& Sons, Ltd.

\section{A B S T R A C T}

\section{Background}

Acid etching of tooth surfaces to promote the bonding of orthodontic attachments to the enamel has been a routine procedure in orthodontic treatment since the 1960s. Various types of orthodontic etchants and etching techniques have been introduced in the past five decades. Although a large amount of information on this topic has been published, there is a significant lack of consensus regarding the clinical effects of different dental etchants and etching techniques.

\section{Objectives}

To compare the effects of different dental etchants and different etching techniques for the bonding of fixed orthodontic appliances.

\section{Search methods}

We searched the following electronic databases: the Cochrane Oral Health Group's Trials Register (to 8 March 2013), the Cochrane Central Register of Controlled Trials (CENTRAL) (The Cochrane Library 2013, Issue 2), MEDLINE via OVID (to 8 March 2013), EMBASE via OVID (to 8 March 2013), Chinese Biomedical Literature Database (to 12 March 2011), the WHO International Clinical Trials Registry Platform (to 8 March 2013) and the National Institutes of Health Clinical Trials Registry (to 8 March 2013). A handsearching group updated the handsearching of journals, carried out as part of the Cochrane Worldwide Handsearching Programme, to the most current issue. There were no restrictions regarding language or date of publication.

\section{Selection criteria}

Randomized controlled trials (RCTs) comparing different etching materials, or different etching techniques using the same etchants, for the bonding of fixed orthodontic brackets to incisors, canines and premolars in children and adults.

\section{Data collection and analysis}

Two review authors extracted data and assessed the risk of bias of included studies independently and in duplicate. We resolved disagreements by discussion among the review team. We contacted the corresponding authors of the included studies to obtain additional information, if necessary. 


\section{Main results}

We included 13 studies randomizing 417 participants with 7184 teeth/brackets. We assessed two studies (15\%) as being at low risk of bias, 10 studies $(77 \%)$ as being at high risk of bias and one study $(8 \%)$ as being at unclear risk of bias.

\section{Self etching primers (SEPs) versus conventional etchants}

Eleven studies compared the effects of SEPs with conventional etchants. Only five of these studies (three of split-mouth design and two of parallel design) reported data at the participant level, with the remaining studies reporting at the tooth level, thus ignoring clustering/the paired nature of the data. A meta-analysis of these five studies, with follow-up ranging from 5 to 37 months, provided low-quality evidence that was insufficient to determine whether or not there is a difference in bond failure rate between SEPs and convention etchants (risk ratio $1.14 ; 95 \%$ confidence interval ( $\mathrm{Cl}) 0.75$ to $1.73 ; 221$ participants). The uncertainty in the $\mathrm{Cl}$ includes both no effect and appreciable benefit and harm. Subgroup analysis did not show a difference between split-mouth and parallel studies.

There were no data available to allow assessment of the outcomes: decalcification, participant satisfaction and cost-effectiveness. One study reported decalcification, but only at the tooth level.

\section{SEPs versus SEPs}

Two studies compared two different SEPs. Both studies reported bond failure rate, with one of the studies also reporting decalcification. However, as both studies reported outcomes only at the tooth level, there were no data available to evaluate the superiority of any of the SEPs over the others investigated with regards to any of the outcomes of this review.

We did not find any eligible studies evaluating different etching materials (e.g. phosphoric acid, polyacrylic acid, maleic acid), concentrations or etching times.

\section{Authors' conclusions}

We found low-quality evidence that was insufficient to conclude whether or not there is a difference in bond failure rate between SEPs and conventional etching systems when bonding fixed orthodontic appliances over a 5- to 37-month follow-up. Insufficient data were also available to allow any conclusions to be formed regarding the superiority of SEPs or conventional etching for the outcomes: decalcification, participant satisfaction and cost-effectiveness, or regarding the superiority of different etching materials, concentrations or etching times, or of any one SEP over another. Further well-designed RCTs on this topic are needed to provide more evidence in order to answer these clinical questions.

\section{PLAIN LANGUAGE SUMMARY}

Preparing tooth surfaces in preparation for the bonding of fixed orthodontic braces

\section{Review question}

The main question addressed by this review is: what is the best method for preparing the enamel on the surface of teeth so as to improve the bonding (sticking) of fixed orthodontic braces?

\section{Background}

Many people need to wear fixed orthodontic devices, such as braces, to correct problems with the teeth and jaw (e.g. overcrowding or front teeth that stick out (protrude) or go too far backwards (retroclined)). How these braces are fixed in place will be of interest to them. In order to attach an orthodontic device, such as a brace, to a tooth, the surface of the appropriate tooth first needs to be prepared so that it can retain the glue or bonding agent used to enable the device to be attached securely. For the past 50 years, the usual way of doing this has been to etch (roughen) the surface of the tooth with acid, commonly phosphoric acid, although maleic acid or polyacrylic acid are also sometimes used. Possible harms of etching include the permanent loss of enamel (hard surface) from the surface of the tooth making it more likely for it to lose calcium or weaken during and after treatment. Recently, to reduce the length of time and complexity of the process, a technique using self etching primers (SEPs) has been developed as an alternative to conventional etchants or acids. However, whether SEPs or conventional etchants are better, and the best SEP, acid, concentration and etching time, remain to be determined.

\section{Study characteristics}

Cochrane Oral Health carried out this review of existing studies, which includes evidence current up to 8 March 2013. This review includes 13 published studies in which a total of 417 children and adults randomly received different tooth preparations before fixed orthodontic braces were bonded to their teeth. Eleven of these studies compared SEPs with conventional etching, and two compared two different SEPS.

\section{Key results}


Only five of the studies provided usable evidence for this review and the combined results did not enable a conclusion to be made about whether or not there is a difference in bond failure (when the orthodontic fixings come away from the tooth) between SEPS and conventional etching. There was also no usable evidence to suggest whether SEPs or conventional etchants lead to less decay around the etching site, or are associated with fewer costs or better participant satisfaction. There was also no usable evidence to enable conclusions to be drawn about which was the best SEP, acid, concentration or etching time.

\section{Quality of the evidence}

The evidence presented is of low quality due to issues with the way in which some of the studies were conducted. 
SUMMARY OF FINDINGS

\section{Summary of findings for the main comparison. Self etching primers compared with conventional etchants for bonding fixed orthodontic brackets}

Participants or population: Children and adults with fixed orthodontic brackets

Settings: Clinical (typically university dental clinics)

Intervention: Self etching primers (one-step etchant and primer system)

Comparison: Conventional etchants (two-step etch and prime method using $37 \%$ phosphoric acid)

\begin{tabular}{|c|c|c|c|c|c|c|}
\hline \multirow[t]{3}{*}{ Outcomes } & \multicolumn{2}{|c|}{ Illustrative comparative risks* $(95 \% \mathrm{Cl})$} & \multirow{3}{*}{$\begin{array}{l}\text { Relative effect } \\
(95 \% \mathrm{Cl})\end{array}$} & \multirow{3}{*}{$\begin{array}{l}\text { No of partici- } \\
\text { pants } \\
\text { (studies) }\end{array}$} & \multirow{3}{*}{$\begin{array}{l}\text { Quality of the } \\
\text { evidence } \\
\text { (GRADE) }\end{array}$} & \multirow[t]{3}{*}{ Comments } \\
\hline & Assumed risk & Corresponding risk & & & & \\
\hline & $\begin{array}{l}\text { Conventional } \\
\text { etchants }\end{array}$ & Self etching primers & & & & \\
\hline $\begin{array}{l}\text { Bond failure rate ( } 5 \text { to } 37 \\
\text { months) }\end{array}$ & 196 per 1000 & $\begin{array}{l}\mathbf{2 2 3} \text { per } \mathbf{1 0 0 0} \\
(147 \text { to } 339)\end{array}$ & $\begin{array}{l}\text { RR } 1.14 \text { (0.75 to } \\
1.73)\end{array}$ & $\begin{array}{l}221 \\
(5)\end{array}$ & $\begin{array}{l}\oplus \oplus \Theta \Theta^{1,2} \\
\text { low }\end{array}$ & $\begin{array}{l}\text { Five more studies, which we } \\
\text { were unable to include in } \\
\text { the meta-analysis, report- } \\
\text { ed mixed results (Additional } \\
\text { Table 2) }\end{array}$ \\
\hline $\begin{array}{l}\text { Decay (decalcification) associ- } \\
\text { ated with or around the etching } \\
\text { field }\end{array}$ & \multicolumn{6}{|c|}{$\begin{array}{l}\text { Only one study (Ghiz 2009) assessed this outcome but data were reported at the tooth level rather than at the participant level and } \\
\text { therefore was not amenable to analysis using Cochrane methods }\end{array}$} \\
\hline Participant satisfaction & \multicolumn{6}{|c|}{ No studies assessed this outcome } \\
\hline Damage to the teeth & \multicolumn{6}{|c|}{ No studies assessed this outcome } \\
\hline
\end{tabular}

${ }^{\star}$ The assumed risk is the median control group risk across studies. The corresponding risk (and its $95 \% \mathrm{Cl}$ ) is based on the assumed risk in the comparison group and the relative effect of the intervention (and its $95 \% \mathrm{Cl}$ ).

Cl: confidence interval; RR: risk ratio

GRADE Working Group grades of evidence

High quality: Further research is very unlikely to change our confidence in the estimate of effect.

Moderate quality: Further research is likely to have an important impact on our confidence in the estimate of effect and may change the estimate.

Low quality: Further research is very likely to have an important impact on our confidence in the estimate of effect and is likely to change the estimate.

Very low quality: We are very uncertain about the estimate. 
wo studies at low risk of bias, one at unclear risk, but two with serious risk of selection bias.

2 Low total number of events and the $95 \% \mathrm{Cl}$ includes both no effect and appreciable benefit and harm. 


\section{B A C K G R O U N D}

\section{Description of the condition}

Orthodontic treatment involves the use of both removable and fixed appliances. It is widely documented that fixed appliances are more efficient at correcting malocclusions than removable appliances (O'Brien 1993; Richmond 1993), and therefore fixed appliances are more commonly used in contemporary orthodontic practice. Fixed orthodontic treatment depends on, among other factors, the successful bonding of orthodontic brackets to tooth enamel. Conventional orthodontic bonding of a bracket using composite relies on the production, by phosphoric acid, of a reproducible etch pattern on the tooth enamel that allows mechanical retention of the adhesive (Buonocore 1955). Although composites, glass ionomers and compomers have been assessed for bracket bonding, composite resins remain the most effective and reliable adhesive available for bonding orthodontic attachments (Mandall 2003). For composite resins, both chemical and light-cured adhesives are used routinely as part of fixed appliance therapy using conventional two-stage enamel etching and priming (Sunna 1998). The conventional bonding of orthodontic brackets to enamel uses the etch-and-rinse bonding approach and provides good adhesive results. However, this bonding approach is time-consuming because a series of steps have to be followed (Aljubouri 2004; Bishara 2001). Even though the acid etching technique is useful in orthodontics, improved techniques are needed to maintain clinically useful bond strengths while minimizing enamel loss and to simplify the technique by reducing the number of steps.

\section{Description of the intervention}

The process of etching tooth surfaces with phosphoric acid in order to bond acrylic resin to tooth enamel was first introduced in 1955 by Buonocore, who used $85 \%$ phosphoric acid for 30 seconds and reported that the bonding strength of acrylic restorative resins was significantly increased by the etching of the enamel surface (Buonocore 1955). In 1965, with the advent of epoxy resin bonding, Newman began to apply these findings to the direct bonding of orthodontic attachments (Newman 1978). It was not until 1977, however, that the first detailed post-treatment evaluation of direct bonding over a full period of orthodontic treatment in a large sample of individuals was published. The clinical implication of this study, that acid etching and bonding would henceforth be widely accepted in orthodontics, has indeed been verified by orthodontists worldwide (Zachrisson 1977). Phosphoric acid (gel or solution) has remained the primary enamel etchant since this technique was introduced. However, other etchants such as maleic acid and polyacrylic acid have been considered as alternatives by various investigators (Olsen 1997).

The introduction of the acid-etch bonding technique has given rise to dramatic changes in the practice of clinical orthodontics. It has several advantages, such as enhancing the ability of the individual to remove plaque, minimizing soft tissue irritation and hyperplastic gingivitis, eliminating the need for separation, facilitating the application of attachments to partially erupted teeth, eliminating post-treatment band spaces, minimizing the risk of decalcification with loose bands, facilitating the detection and treatment of dental caries, as well as resulting in a better esthetic appearance for the recipient (Zachrisson 1976). However, it has been widely reported that permanent loss of enamel during the etching procedure may make the enamel surface more susceptible to decalcification during and after orthodontic treatment (Sadowsky 1976).

When bonding fixed orthodontic appliances to enamel, most orthodontists use a conventional technique that involves separate steps of etching and conditioning of tooth enamel. Initially the enamel is etched with etchant and then a hydrophilic primer is placed on the etched, rinsed and dried surface. The brackets are then bonded with an adhesive resin composite. This procedure has some obvious disadvantages. First, a potential problem can be contamination by saliva or from a faulty air or water syringe tip after the enamel is prepared for resin bonding using the etchant and a separate primer. Second, these multiprocedural steps can be very time consuming. Therefore, in 1998, Bishara et al applied a modified one-step etchant-and-primer system to clinical orthodontics and demonstrated that use of such a system to bond orthodontic brackets to tooth enamel could provide acceptable shear bond strength (Bishara 1998). This procedure can reduce the number of procedural steps involved in the application, and decrease technique sensitivity and chair-side time, without compromising outcome.

\section{How the intervention might work}

There is a significant lack of consensus regarding the effectiveness of different dental etchants. A 50\% phosphoric acid concentration has been suggested by Retief (Retief 1973), whereas Silverstone and Gorelick consider a 30\% to $50 \%$ phosphoric acid concentration ideal (Gorelick 1977; Silverstone 1974). To reduce the potential risk of significant enamel loss, various investigators have considered alternative ways of treating the enamel surface before the bonding procedure, including the use of maleic acid or polyacrylic acid (Olsen 1997; Triolo 1993). Bishara et al compared different enamel etching materials and indicated that the use of polyacrylic acid resulted in a $30 \%$ reduction in bond strength compared with the use of phosphoric acid (Bishara 1993). In the early 1990s, Barkmeier and Erickson compared the use of $10 \%$ maleic acid and $37 \%$ phosphoric acid, and reported that the resulting bond strengths were essentially similar (Barkmeier 1994).

There is still controversy as to the effectiveness of self etching primers (SEPs) compared with conventional etchants. Barkmeier et al examined the effect of Clearfil Liner Bond 2 on enamel through shear bond testing and demonstrated that the resin penetrated the enamel surface and that adequate conditioning was achieved (Barkmeier 1995). Bishara and Gordon compared the shear bond strength of orthodontic brackets attached to enamel that had been etched using 37\% phosphoric acid, 10\% maleic acid or an acidic primer solution and concluded that acidic primer systems used to bond orthodontic attachments to tooth enamel could provide acceptable shear bond strength (Bishara 1998). Ryan et al compared the orthodontic bonding strength of a recently developed SEP and a conventional etchant, and found no significant difference between them (Ryan 2002).

\section{Why it is important to do this review}

Although enamel etching has been widely accepted by professionals for the bonding of fixed orthodontic braces, and vast amounts of information on this topic have been published, there is a significant lack of consensus regarding the clinical efficacy and security of the application of enamel etching. Controversy remains as to: (1) the effectiveness of different dental etchants; (2) the 
optimal etching duration and concentration of specific etchants; (3) the effectiveness of SEPs compared with conventional etchants; and (4) the clinical efficacy of different SEPs.

Such uncertainty indicates that there is a need to evaluate the existing evidence for this procedure and identify best practice and further areas for good-quality primary research.

\section{O B J E C T IVES}

To compare the effects of different dental etchants and different etching techniques for the bonding of fixed orthodontic appliances.

\section{METHODS}

\section{Criteria for considering studies for this review}

\section{Types of studies}

We included randomized controlled trials (RCTs) comparing different etching materials or different etching techniques. These include split-mouth trials using quadrants (even if contralateral quadrants are given the same intervention) but not those randomizing individual teeth or using alternate teeth, with the initial selection of the teeth sequence being randomized.

\section{Types of participants}

We included participants, both children and adults, with fixed orthodontic brackets attached to their incisors, canines and premolars. We excluded individuals with a cleft lip or palate or both, or with other craniofacial deformities/syndromes. We also excluded those with hypoplastic or fluorotic teeth.

\section{Types of interventions}

Any kind of etching materials and techniques used in the intervention group compared with different etching materials, times and acid concentrations, or an alternative etching technique in the control group.

\section{Types of outcome measures}

We excluded studies that compared different dental etchants or different etching techniques but did not report any of the outcomes listed below.

\section{Primary outcomes}

- Bond failure rate of braces (the rate at which braces fall off the teeth during treatment).

\section{Secondary outcomes}

- The presence or absence of decay (decalcification) associated with or around the etching field.

- Participant satisfaction.

- Cost of treatment.

\section{Search methods for identification of studies}

For the identification of studies included or considered for this review, we developed detailed search strategies for each database searched. These were based on the search strategy developed for MEDLINE (OVID) but revised appropriately for each database. The search strategy used a combination of controlled vocabulary and free text terms, and was linked with the Cochrane Highly Sensitive
Search Strategy for identifying RCTs in MEDLINE: sensitivity maximizing version (2008 revision), as referenced in Chapter 6.4.11.1 and detailed in Box 6.4.c of the Cochrane Handbook for Systematic Reviews of Interventions Version 5.1.0 (Higgins 2011). Details of the MEDLINE search are provided in Appendix 3. The search of EMBASE was linked to the Cochrane Oral Health Group filter for identifying RCTs (see Appendix 4 for details).

\section{Electronic searches}

We searched the following electronic databases for relevant studies:

- Cochrane Oral Health Group's Trials Register (to 8 March 2013) (Appendix 1);

- Cochrane Central Register of Controlled Trials (CENTRAL) (The Cochrane Library 2013, Issue 2) (Appendix 2);

- MEDLINE via OVID (1948 to 8 March 2013) (Appendix 3);

- EMBASE via OVID (1980 to 8 March 2013) (Appendix 4);

- WHO International Clinical Trials Registry Platform (to 8 March 2013) (Appendix 5);

- National Institutes of Health Clinical Trials Registry (www.ClinicalTrials.gov) (to 8 March 2013) (Appendix 6);

- Chinese Biomedical Literature Database (CBM, 1978 to 12 March 2011, in Chinese).

Cochrane Oral Heath's Information Specialist, Anne Littlewood, searched the first six databases; we searched the remainder.

\section{Searching other resources}

We searched the online abstract indices of the conference proceedings for meetings, such as the AAO (American Association of Orthodontics), IADR (International Association for Dental Research), British Orthodontic Conference and European Orthodontic Conference, to find any relevant ongoing or unpublished trials.

We contacted manufacturers and first authors of included trial reports in order to identify any unpublished or ongoing clinical trials, and to clarify data as necessary. We screened reference lists of included studies for further trials.

In June 2013, a handsearching group updated the handsearching of the following journals to the most current issue,as part of the Cochrane Worldwide Handsearching Programme:

- American Journal of Orthodontics and Dentofacial Orthopedics (1970 to March 2012);

- Angle Orthodontist (1978 to March 2012);

- European Journal of Orthodontics (1979 to March 2012);

- Journal of Orthodontics (formerly British Journal of Orthodontics) (1978 to March 2012);

- Journal of Clinical Orthodontics (1978 to March 2012);

- Orthodontics and Craniofacial Research (1978 to March 2012).

In addition, the following Chinese journals were handsearched within relevant fields:

- Journal of Stomatology (1981 to June 2013);

- Chinese Journal of Dental Material and Devices (1992 to June 2013); 
- West China Journal of Stomatology (1983 to June 2013);

- Journal of Clinical Stomatology (1985 to June 2013);

- Journal of Comprehensive Stomatology (1985 to June 2013);

- Journal of Modern Stomatology (1987 to June 2013);

- Chinese Journal of Stomatology (1953 to June 2013);

- Beijing Journal of Stomatology (1993 to June 2013);

- Shanghai Journal of Stomatology (1992 to June 2013).

\section{Data collection and analysis}

\section{Selection of studies}

Two review authors assessed the titles and abstracts (when available) of all studies resulting from the search, independently and in duplicate. We obtained full copies of all relevant and potentially relevant studies (those which appeared to meet the inclusion criteria), or studies for which the information in the titles and abstracts was not sufficient to make a clear decision. The same two review authors assessed full text copies independently and we resolved any disagreements on eligibility through discussion, involving a third review author where necessary. We excluded any study that did not match the inclusion criteria and their details and reasons for exclusion were noted in the Characteristics of excluded studies table. The review authors were not blinded to author(s), institution or site of publication.

\section{Data extraction and management}

Two review authors independently extracted data from the included studies using a specially designed data extraction table that was pilot-tested on four of the included studies. Contents of the data extraction included the following.

- Basic information of the trial: trial ID, title, authors, journal information, reviewer ID, date of data extraction.

- Eligibility re-assessment: all items in the inclusion criteria, final decision.

- Study design: methods of randomization, allocation concealment and blinding, centres, country, time frame, ethics.

- Participant information: inclusion and exclusion criteria, demographics (age, sex, etc), types of malocclusion, number of participants in each group, baseline status.

- Intervention and comparison: details of the intervention and control groups, details of the active treatments applied to both groups, follow-up period, number of participants lost to followup and reasons.
- Outcome: outcome variables and assessment methods, observation time, detailed results (including a $2 \times 2$ table for dichotomous data, and means and standard deviations (SD) or medians and quarters for continuous data ( $\mathrm{P}, \mathrm{t}, \mathrm{Chi}^{2}$, etc.)).

- Correspondence: contact addresses of original authors, questions to be asked.

\section{Assessment of risk of bias in included studies}

Two review authors carried out the assessment of risk of bias in the included studies, independently and in duplicate, using The Cochrane Collaboration's two-part tool for assessing risk of bias. In the case of any discrepancies, a third review author also assessed the study. We completed a 'Risk of bias' table under the Characteristics of included studies for each study, as outlined in the Cochrane Handbook for Systematic Reviews of Interventions (Higgins 2011).

Assessment of the risk of bias in included studies was carried out for the following seven domains:

1. sequence generation (selection bias);

2. allocation concealment (selection bias);

3. blinding of participants and personnel (performance bias);

4. blinding of outcome assessors (detection bias);

5. incomplete outcome data (attrition bias);

6. selective reporting (reporting bias);

7. other bias.

We documented a description of what was reported to have happened in the study for each domain within each 'Risk of bias' table, together with our assessment of the risk of bias for that domain: either 'low risk', 'unclear risk' or 'high risk'. We contacted the study authors to seek clarification in the event of uncertain data.

For objective outcomes, such as the primary outcome of this review (bond failure rate), we considered that blinding was unlikely to have any effect, and thus assigned a judgement of 'low risk' of performance bias to all studies that reported this outcome. We grouped objective outcomes together, as suggested in the Cochrane Handbook for Systematic Reviews of Interventions (Higgins 2011).

We summarized risk of bias in the included studies using the following criteria.

\begin{tabular}{llll}
\hline Risk of bias & Interpretation & In outcome & In included studies \\
\hline Low risk of bias & $\begin{array}{l}\text { Plausible bias unlikely to seri- } \\
\text { ously alter the results }\end{array}$ & $\begin{array}{l}\text { Low risk of bias for all key } \\
\text { domains }\end{array}$ & $\begin{array}{l}\text { Most information is from studies at low risk of } \\
\text { bias }\end{array}$ \\
\hline Unclear risk of bias & $\begin{array}{l}\text { Plausible bias that raises some } \\
\text { doubt about the results }\end{array}$ & $\begin{array}{l}\text { Unclear risk of bias for } \\
\text { one or more key domains }\end{array}$ & $\begin{array}{l}\text { Most information is from studies at low or un- } \\
\text { clear risk of bias }\end{array}$ \\
\hline High risk of bias & $\begin{array}{l}\text { Plausible bias that seriously } \\
\text { weakens confidence in the re- } \\
\text { sults }\end{array}$ & $\begin{array}{l}\text { High risk of bias for one } \\
\text { or more key domains }\end{array}$ & $\begin{array}{l}\text { The proportion of information from studies at } \\
\text { high risk of bias is sufficient to affect the inter- } \\
\text { pretation of results }\end{array}$ \\
\hline
\end{tabular}


The risk of bias is presented graphically in Figure 1.

Figure 1. Risk of bias summary: review authors' judgments about each risk of bias item for each included study.

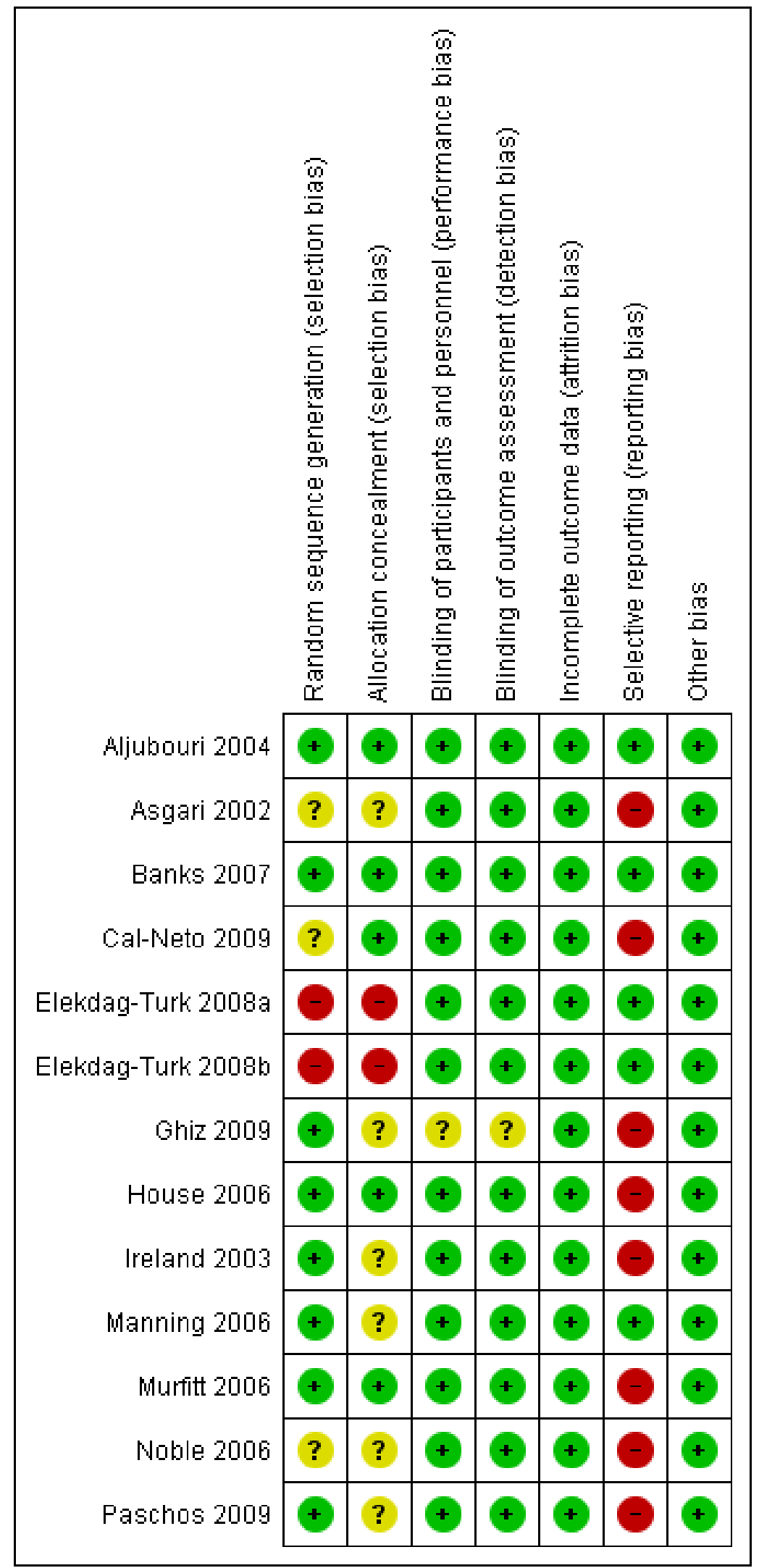




\section{Measures of treatment effect}

The measures of treatment effect differed according to data type. We treated bond failure rate as dichotomous data (as only failure or no failure was reported). We would have treated the secondary outcomes as dichotomous data or continuous data depending on the individual study.

\section{Dichotomous data}

We calculated risk ratios (RR) and 95\% confidence intervals (Cls) for dichotomous data.

\section{Continuous data}

We would have calculated mean differences (MD) and 95\% Cls for continuous outcomes that were assessed using the same scale, and standardized mean differences (SMD) and $95 \% \mathrm{Cls}$ if different scales were used.

\section{Unit of analysis issues}

We based the unit of analysis on the participant, not on the tooth or quadrant; however, we also considered the analysis of studies with non-standard designs.

\section{Parallel studies}

Because some of the original reports of parallel studies could include inappropriate analyses, as described in the Cochrane Handbook for Systematic Reviews of Interventions (Higgins 2011), in order to avoid such statistical errors, we intended to calculate approximate analyses according to guidelines from the handbook.

\section{Split-mouth studies}

We assessed the carry-over effect for all split-mouth studies. We intended to approximate a paired analysis, following the guidance of the Cochrane Handbook for Systematic Reviews of Interventions (Higgins 2011). In the case of an ideal study (i.e. one that reported means and SD for both groups, and the MD and SD/standard error (SE) between the two groups), we intended to calculate intra-group correlation coefficients (ICC); if we identified more than one ideal study, we intended to calculate the mean ICC, which we would have adopted in the calculation of the MD and SD/SE for other, similar split-mouth studies. If no ideal study was identified, then we assumed that the ICC was 0.5 .

\section{Studies with multiple intervention arms}

For RCTs with multiple treatment arms, we intended to combine similar arms. If this was not possible, we would select the most relevant treatment and control groups for analyses.

\section{Dealing with missing data}

Where data were missing, we adopted the following strategies.

- Contact of study authors to request missing data whenever possible.

- If SD was not provided but $\mathrm{SE}, 95 \% \mathrm{Cl}, \mathrm{t}$ or $\mathrm{P}$ values were available, we intended to use these data to calculate exact SD (under such circumstances, there was no need to request such data from the study author).
- If both mean and SD were reported in graphical rather than numerical format, we planned to amplify the relevant graphic and calculate or measure the mean and SD.

\section{Assessment of heterogeneity}

We assessed heterogeneity using the $\mathrm{Chi}^{2}$ test, where a $\mathrm{P}$ value less than 0.1 indicates statistically significant heterogeneity. We quantified heterogeneity using the $\mathrm{I}^{2}$ statistic, using the following rough guide to interpretation given in the Cochrane Handbook for Systematic Reviews of Interventions (Higgins 2011):

- $0 \%$ to $40 \%$ : heterogeneity may not be important;

- 30\% to 60\%: may represent moderate heterogeneity;

- $50 \%$ to $90 \%$ : may represent substantial heterogeneity;

- $75 \%$ to $100 \%$ : may represent considerable heterogeneity.

If heterogeneity greater than $50 \%$ was present, we planned to attempt to explain the heterogeneity based on the clinical characteristics of the included studies and to perform subgroup analyses to explore the lack of homogeneity.

\section{Assessment of reporting biases}

If we included more than 10 studies in a meta-analysis, we planned to use a funnel graph to assess publication bias, using Egger's or Begg's method (Begg 1994; Egger 1997). Asymmetry of the funnel plot and a $P$ value less than 0.10 would have been taken as indicating the possibility of reporting bias.

\section{Data synthesis}

We carried out meta-analyses only of studies reporting the same comparisons and outcomes. We combined RR for dichotomous outcomes (and would have combined MD if we had found any usable continuous data) using a random-effects model. We intended to use a fixed-effect model if we identified fewer than four studies suitable for meta-analysis.

\section{Subgroup analysis and investigation of heterogeneity}

To identify reasons for clinical or methodological heterogeneity in any meta-analysis and to explore the effect of modification of participants and treatment types, we carried out subgroup analyses, where sufficient numbers of studies were available, according to:

- study design: parallel design or split-mouth design;

- interventions: different brace systems (e.g. self ligating or edgewise brackets systems), different observation periods (e.g. short term or long term) or different etching times.

\section{Sensitivity analysis}

Where feasible, and if sufficient numbers of studies were found, we intended to carry out sensitivity analyses to assess all included studies by:

- excluding any unpublished studies;

- excluding studies with a high risk of bias;

- comparing different models of intention-to-treat analysis (worst-case scenario analysis versus best-case scenario analysis);

- using different assumptions of ICC (0.3 versus 0.7$)$. 


\section{Summary of findings table}

We developed a summary of findings table using GRADEPro software in order to assess the quality of the body of evidence (GRADE 2004). This was assessed with reference to the overall risk of bias of the included studies, the directness of the evidence, the inconsistency of the results, the precision of the estimates and the risk of publication bias. The quality of the body of evidence for each assessable outcome was categorized as high, moderate, low or very low.

\section{RES U L T S}

\section{Description of studies}

\section{Results of the search}

We identified 421 publications during the searching process, of which 395 were discarded after reviewing the titles and abstracts.
We obtained full articles for the remaining 26 publications, and excluded a further 12 after screening. As two of the remaining 14 publications that met the inclusion criteria for this review were reports of the same RCT, we linked these together under a single primary reference (Manning 2006). We therefore included 13 RCTs in this review (Aljubouri 2004; Asgari 2002; Banks 2007; Cal-Neto 2009; Elekdag-Turk 2008a; Elekdag-Turk 2008b; Ghiz 2009; House 2006; Ireland 2003; Manning 2006; Murfitt 2006; Noble 2006; Paschos 2009). For details of the studies examined and reasons for inclusion or exclusion, see the Characteristics of included studies and Characteristics of excluded studies tables. We outline the process of study identification in Figure 2. 
Figure 2. Flow diagram of study inclusion.

$$
\begin{aligned}
& 421 \text { records identified through } \\
& \text { database searching }
\end{aligned}
$$

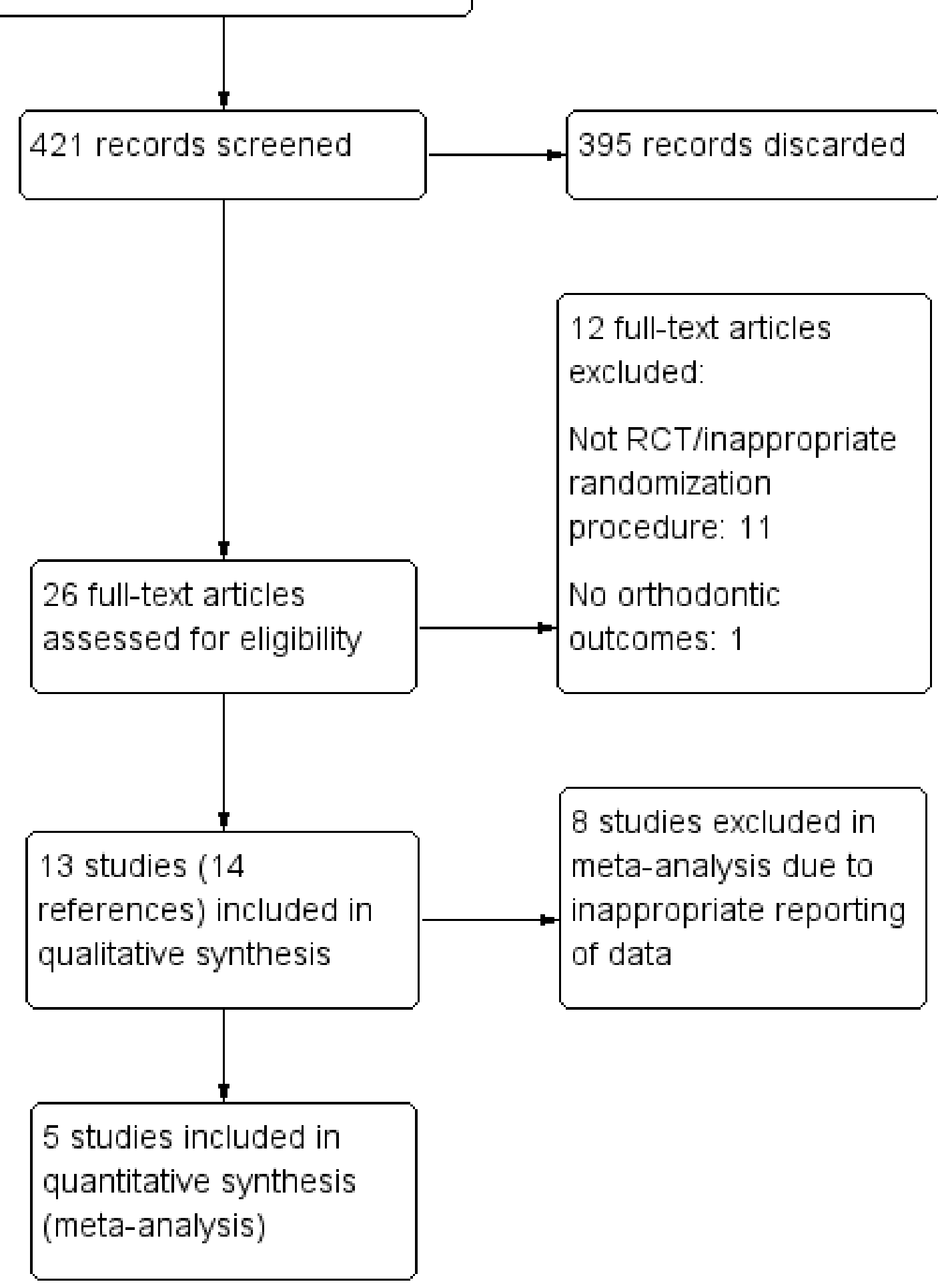

\section{Included studies}

See Characteristics of included studies table. 


\section{Design}

Ten of the included studies were of split-mouth design, and the remaining three were of parallel design. In nine of the splitmouth studies (Aljubouri 2004; Asgari 2002; Elekdag-Turk 2008a; Elekdag-Turk 2008b; House 2006; Ireland 2003; Murfitt 2006; Noble 2006; Paschos 2009) participants were randomly allocated to have the upper right and lower left quadrants bonded with the same etching technique, using either a self etching primer (SEP) or a conventional etching system; the remaining quadrants were bonded using the alternative technique. In the remaining splitmouth study (Ghiz 2009), participants were randomly assigned to have a conventional etching system used on one arch and an SEP on the other arch. In the three parallel studies (Banks 2007; CalNeto 2009; Manning 2006), participants were randomized to receive conventional etching or SEP.

\section{Sample sizes}

The sample size ranged from 20 to 60 participants with 339 to 871 brackets. Seven of the 13 studies undertook a priori sample size calculation on the basis of previous research in order to detect a significant difference between the two intervention groups (Aljubouri 2004; Banks 2007; Cal-Neto 2009; House 2006; Manning 2006; Murfitt 2006; Paschos 2009), whereas sample size calculation was not mentioned in the remaining six studies. We contacted the authors of four of these studies and were informed that the authors of three studies carried out a power analysis from previous studies as a guideline for sample size determination (Elekdag-Turk 2008a; Elekdag-Turk 2008b; Ghiz 2009). However, we received no reply from the authors of the remaining study (Ireland 2003).

\section{Setting}

Of the 13 studies, five were conducted in UK (Aljubouri 2004; Banks 2007; House 2006; Ireland 2003; Manning 2006), three in the USA (Asgari 2002; Ghiz 2009; Noble 2006), two in Turkey (Elekdag-Turk 2008a; Elekdag-Turk 2008b), one in Brazil (Cal-Neto 2009), one in New Zealand (Murfitt 2006) and one in Germany (Paschos 2009).

\section{Participants}

In total, this systematic review included 417 participants with 7184 teeth/brackets. The age distribution ranged from 11 to 36 years, and most of the participants were teenagers. Most studies reported inclusion/exclusion criteria for the selection of participants. Five studies did not report participants' sex (Asgari 2002; Ghiz 2009; House 2006; Ireland 2003; Noble 2006), whereas four studies did not report age (Asgari 2002; Ghiz 2009; House 2006; Ireland 2003).

\section{Interventions}

Eleven studies compared the effectiveness of SEPs with conventional etchants for the bonding of fixed orthodontic appliances (Aljubouri 2004; Asgari 2002; Banks 2007; Cal-Neto 2009; Elekdag-Turk 2008a; Elekdag-Turk 2008b; Ghiz 2009; House 2006; Ireland 2003; Manning 2006; Murfitt 2006). Ten of these studies compared Transbond Plus SEP (3M Unitek) and 37\% phosphoric acid. One study compared Ideal 1 SEP (GAC Orthodontic Products) and $37 \%$ phosphoric acid (House 2006). Finally, two studies compared two SEPs: Transbond Plus (3M Unitek) versus Clearfil Protect Bond (Kuraray Medical) (Paschos 2009) and Transbond Plus (3M Unitek) versus First Step SEP (Reliance Orthodontic Products) (Noble 2006).
We identified no eligible trial that examined the effects of conventional etchants with respect to different etching concentrations or etching times for the bonding of fixed orthodontic appliances.

\section{Outcomes}

Some of the outcomes of interest in this systematic review were evaluated in the included studies.

1. Bond failure rate: overall bond failure rate (Aljubouri 2004; Asgari 2002; Banks 2007; Cal-Neto 2009; Elekdag-Turk 2008a; Elekdag-Turk 2008b; House 2006; Ireland 2003; Manning 2006; Murfitt 2006; Noble 2006; Paschos 2009); bond failure rate per participant (Aljubouri 2004; Banks 2007; Elekdag-Turk 2008a; Elekdag-Turk 2008b; Manning 2006) (for Elekdag-Turk 2008a and Elekdag-Turk 2008b, unpublished participant-level data was provided on request by the study authors); and bond failure rate distributions with respect to dental arch, type of tooth and participant sex (Banks 2007; Cal-Neto 2009; Elekdag-Turk 2008a; Elekdag-Turk 2008b; Manning 2006; Murfitt 2006; Noble 2006).

2. The presence or absence of decay (decalcification) associated with or around the etching field (Ghiz 2009; Paschos 2009).

No participant-centered outcomes, such as satisfaction or the cost or duration of treatment, were reported in any of the included studies.

\section{Excluded studies}

See Characteristics of excluded studies table for further details.

We excluded 12 studies from this review. Eleven of these studies were either not RCTs or there were problems with the randomization procedure (i.e. teeth were alternately/sequentially randomized). One study did not report any orthodontic outcomes.

\section{Risk of bias in included studies}

See the 'Risk of bias' tables within Characteristics of included studies for further details. For a graphical summary, see Figure 1.

We assessed two studies as being at low risk of bias (Aljubouri 2004; Banks 2007) and 10 studies as being at high risk of bias (Asgari 2002; Cal-Neto 2009; Elekdag-Turk 2008a; Elekdag-Turk 2008b; Ghiz 2009; House 2006; Ireland 2003; Murfitt 2006; Noble 2006; Paschos 2009). We assessed the remaining study as being at unclear risk of bias (Manning 2006).

\section{Allocation}

\section{Sequence generation}

Although all of the 13 included studies mentioned random allocation, after examination of the publications and further contact with several study authors, we considered only eight studies to be at low risk of bias for this domain (Aljubouri 2004; Banks 2007; Ghiz 2009; House 2006; Ireland 2003; Manning 2006; Murfitt 2006; Paschos 2009). Four of these studies used random number tables for random sequence generation (Banks 2007; House 2006; Ireland 2003; Manning 2006), one used coin tossing (Ghiz 2009), one used random permuted blocks (Murfitt 2006), one used drawing lots (Paschos 2009) and the remaining study stated that the randomization process was carried out by a trial statistician, which is likely to have been done adequately (Aljubouri 
2004). Two studies by the same authors used coin tossing for the first participant, and then alternation afterwards. As alternation is not true randomization (Higgins 2011), we considered these two studies to be at high risk of bias for this domain (ElekdagTurk 2008a; Elekdag-Turk 2008b). The remaining three trials did not describe the method of sequence generation and we assessed these as being at unclear risk of bias (Asgari 2002; Cal-Neto 2009; Noble 2006).

\section{Allocation concealment}

Five studies used sealed envelopes to conceal the allocation sequence from all those involved in the studies, and we therefore assessed these as being at low risk of bias for this domain (Aljubouri 2004; Banks 2007; Cal-Neto 2009; House 2006; Murfitt 2006). Two studies that used coin tossing to allocate the first participant, and then alternation afterwards, could not have concealed the allocation sequence and we therefore considered these studies to be at high risk of bias for this domain (Elekdag-Turk 2008a; ElekdagTurk 2008b). There was not enough information in the remaining six studies to determine whether or not the sequence was adequately concealed, so we judged these studies to be at unclear risk of bias for this domain (Asgari 2002; Ghiz 2009; Ireland 2003; Manning 2006; Noble 2006; Paschos 2009).

\section{Blinding}

\section{Participants and personnel (performance bias)}

The primary outcome of this review (bond failure rate) is highly objective and we considered that blinding was unlikely to have any effect on the outcome; hence, we assigned a judgement of 'low risk' of bias for this domain throughout. One study did not include our primary outcome, and measured only enamel decalcification and oral hygiene compliance (Ghiz 2009). As the outcomes in this study were considered more subjective, and blinding was unclear in the report, we considered this study to be at unclear risk of bias for this domain. We considered the remaining 12 studies to be at low risk of bias for this domain.

\section{Outcome assessment (detection bias)}

For the same reasons stated above, we assessed one study as being at unclear risk of bias (Ghiz 2009) and the remaining 12 studies to be at low risk of bias for this domain.

\section{Incomplete outcome data}

In eight studies there were no drop-outs (Aljubouri 2004; Asgari 2002; Elekdag-Turk 2008b; Ghiz 2009; House 2006; Ireland 2003; Noble 2006; Paschos 2009). In the remaining five studies, the number of drop-outs were minimal and clearly described (Banks 2007; Cal-Neto 2009; Elekdag-Turk 2008a; Manning 2006; Murfitt 2006). Thus, we assessed all 13 studies as being at low risk of bias for this domain.

\section{Selective reporting}

In all 13 studies, the outcomes stated in the methods section of each study were reported in the results section. However, in eight studies we considered the reporting inappropriate as data were reported at tooth level rather than at participant level (Asgari 2002; Cal-Neto 2009; Ghiz 2009; House 2006; Ireland 2003; Murfitt 2006; Noble 2006; Paschos 2009). Furthermore, teeth were treated independently in analyses, ignoring the clustering of teeth within the mouth. We were therefore unable to use the data from these studies in a meta- analysis. For these reasons, we assessed all eight studies as being at high risk of bias for this domain. We assessed the remaining five studies as being at low risk of bias for this domain: three reported data at the participant level (Aljubouri 2004; Banks 2007; Manning 2006), and two provided such data on request (Elekdag-Turk 2008a; Elekdag-Turk 2008b).

We believe it is important to point out that none of the included studies mentioned a previously published protocol.

\section{Other potential sources of bias}

We were not able to identify any other sources of bias in any of the 13 studies, and they were all considered to be at low risk of bias for this domain

\section{Effects of interventions}

See: Summary of findings for the main comparison Self etching primers compared with conventional etchants for bonding fixed orthodontic brackets

\section{Self etching primers versus conventional etchants}

Although 11 RCTs compared the effect of SEPs and conventional etchants, a majority of the results could not be used for further analysis because the outcomes were reported at tooth level rather than at participant level. We considered only five studies, which reported the effects of different etching techniques at participant level, suitable for meta-analysis (e.g. mean bond failure rate per participant).

\section{Mean bond failure rate per participant}

Five of the included studies, with 221 participants, reported the results of the bond failure rate at participant level and were pooled in a meta-analysis (Aljubouri 2004; Banks 2007; ElekdagTurk 2008a; Elekdag-Turk 2008b; Manning 2006). Two of these studies were parallel-designed RCTs with low heterogeneity (Banks 2007; Manning 2006), and three were split-mouth designed RCTs with moderate heterogeneity (Aljubouri 2004; Elekdag-Turk 2008a; Elekdag-Turk 2008b). We present the raw data for this outcome in Additional Table 1. We assessed two studies as being at low risk of bias (Aljubouri 2004; Banks 2007), two studies as being at high risk of bias (Elekdag-Turk 2008a; Elekdag-Turk 2008b) and the remaining study as at unclear risk of bias (Manning 2006). The duration of follow-up in three of the studies was 12 months (Aljubouri 2004; Elekdag-Turk 2008a; Manning 2006), whereas one study had six months of follow-up (Elekdag-Turk 2008b) and in the remaining study follow-up ranged from 5 to 37 months (Banks 2007).

We considered the evidence insufficient to determine whether or not there is a difference in the bond failure rate between the SEP group and the conventional etching group (risk ratio (RR) 1.14; 95\% confidence interval $(\mathrm{Cl}) 0.75$ to 1.73 ) (Analysis 1.1). The uncertainty in the $\mathrm{Cl}$ includes both no effect and appreciable benefit and harm. Heterogeneity was low $\left(I^{2}=18 \%\right)$ and we considered this as probably not important. We conducted a subgroup analysis of the two types of study design to see whether it was appropriate to combine them in the meta-analysis. There is no evidence that the proportion of bond failures is different for SEP or conventional etchants, either in the subgroup of split-mouth studies (RR 1.09; $95 \% \mathrm{Cl} 0.37$ to 3.26 ) or in the subgroup of parallel studies (RR 1.14; $95 \% \mathrm{Cl} 0.74$ to 1.76 ). The test for subgroup differences was not 
significant $(P$ value $=0.94)$, indicating that it was appropriate to combine both types of study in the meta-analysis.

Five other studies compared SEPs and conventional etchants but did not report the mean bond failure rate per participant (Asgari 2002; Cal-Neto 2009; House 2006; Ireland 2003; Murfitt 2006). These studies reported bond failure rate at the tooth level, and the results were mixed (see Table 2).

\section{Presence or absence of decay (decalcification) associated with or around the etching field}

Only one study reported this outcome (Ghiz 2009). This was a split-mouth designed RCT involving 25 participants with 469 brackets, comparing enamel decalcification between an SEP group and a conventional etching group. However, the decalcification score was reported at tooth level rather than at participant level. We considered the evidence insufficient to conclude whether or not there is a difference in decalcification between SEPs and conventional etching.

\section{Self etching primers versus self etching primers}

Two split-mouth studies compared two different SEPs (Noble 2006; Paschos 2009). However, the failure rates (and decalcification outcomes in Paschos 2009) were reported at tooth level rather than at participant level. We considered the evidence insufficient to conclude whether or not there is a difference in bond failures or decalcification between the different SEPs.

\section{DISCUSSION}

\section{Summary of main results}

The objective of this review was to evaluate the effects of different etchants and etching techniques for the bonding of fixed orthodontic braces to tooth enamel. We included 13 RCTs that satisfied the inclusion criteria in this review.

Eleven studies compared the effectiveness of self etching primers (SEPs) with conventional etchants for bonding fixed orthodontic appliances. We considered only five of these studies, which reported data on bond failure rate at the participant level, suitable for inclusion in a meta-analysis (Aljubouri 2004; Banks 2007; Elekdag-Turk 2008a; Elekdag-Turk 2008b; Manning 2006). We assessed the body of evidence for this comparison and outcome, using GRADE (GRADE 2004) which incorporates risk of bias of the included studies, the directness of the evidence, the inconsistency of the results, the precision of the estimates and the risk of publication bias (see Summary of findings for the main comparison). We assessed this body of evidence, from five studies analyzing 221 participants and with follow-up ranging from 5 to 37 months, as being low quality and insufficient to conclude whether or not there is a difference in the bond failure rate of SEPS and conventional etchants. There was a lot of uncertainty in the results, with the 95\% confidence interval including both the possibility that SEPs have fewer failures, and that conventional etchants have fewer failures. Five other studies that compared SEPs with conventional etchants, but analyzing bond failure at the tooth level, also reported mixed results (Additional Table 2).

Two studies compared two different SEPs (Noble 2006; Paschos 2009). Neither study reported data at the participant level and we therefore consider that there is no evidence for the superior effects of any one of the SEPs investigated over the others.

\section{Overall completeness and applicability of evidence}

We used a thorough and systematic searching process, outlined in the 'Methods' section of this systematic review, in order to ensure completeness and maximize external validity. However, this systematic review has not been able to meet its objective as the results regarding bond failures were inconclusive. In addition, no eligible RCTs were found that compared the effects of different etching materials (e.g. phosphoric acid, polyacrylic acid, maleic acid), concentrations or etching times for the bonding of fixed orthodontic appliances. Furthermore, we identified only two eligible RCTs that compared different SEPs. Neither study compared the same two SEPs and neither study reported data at the participant level, which meant we were unable to perform a meta-analysis on this comparison, and therefore were unable to form any conclusions on which is the most effective SEP.

We identified a number of additional eligible studies that we did not include in the meta-analysis, as they presented data by tooth rather than by participant. These studies had frequently analyzed results using the $\mathrm{Chi}^{2}$ test, thus failing to take the pairing of the data within participants' mouths into account. We also excluded the data from these studies as teeth were treated independently in the analysis, ignoring the clustering of teeth within the mouth. As the participant is the unit of assessment for both bonding systems, it would have been more correct to report the mean bond failure rate (or mean decalcification score) per participant rather than the overall outcomes at tooth level, which can obscure the true nature of the data. This has been strongly recommended in a previous systematic review (Mandall 2003).

Only two of the included studies dealt with the effect of different etching techniques on the prevention of enamel decalcification (Ghiz 2009; Paschos 2009). However, they both reported data at tooth level. Any difference in the presence or absence of decay (decalcification) associated with or around the etching field is an important outcome, as fixed orthodontic appliances make it difficult for recipients to maintain adequate oral hygiene during treatment. Several studies have found increased plaque around orthodontic appliances (O'Reilly 1987; Ogaard 1988).

No studies reported the outcomes of participant satisfaction or treatment cost-effectiveness, which are important outcomes that should be considered in future studies. The cost of the etching material, together with the bonding time and overall number of appointments required, as well as any additional appointments (e.g. for bracket rebonding because of failure) may play a key role in the selection of etching material and etching technique.

The current limited volume of evidence on the primary outcome of this review (bond failure rate) is not conclusive in demonstrating improved clinical outcomes for one method of etching over another. This may encourage the routine clinical use of SEPs as a good alternative to conventional etching as use of SEPS is associated with fewer clinical steps, less chair-side time and a lower risk of salivary contamination. Further, high-quality RCTs measuring all relevant outcomes and reporting results at a participant level are required before definitive conclusions and recommendations can be made with regard to enamel etching for the bonding of fixed orthodontic braces. 


\section{Quality of the evidence}

We included 13 RCTs and 417 participants with 7184 teeth/ brackets in this systematic review. Of the five studies comparing conventional etchants and SEPs that were suitable for pooling in a meta-analysis for the outcome of bond failure rate, we considered two to be at low risk of bias overall, two to be at high risk and one to be at unclear risk. We downgraded the quality of the body of evidence due to serious concerns about the risk of selection bias in two of the studies, and also as a result of the imprecision of the results (there were a low number of events and the 95\% confidence interval includes both no effect and an appreciable benefit and harm). The results therefore do not allow us to draw a robust conclusion regarding the objective of the review.

Many recent clinical trials comparing bonding systems have used the split-mouth design where, typically, the mouth of each participant is divided into quadrants and the teeth in the maxillary left and mandibular right quadrants receive one pre-treatment, and the teeth in maxillary right and mandibular left quadrants receive the alternative pre-treatment. The advantage of this is that factors pertaining to the participant (e.g. poor care of appliances) will be accounted for evenly, since each participant is his/her own control. However, one bonding agent might affect the performance of the other, and the bracket bonding technique might be altered and may not truly reflect clinical practice. Alternatively, the possibility of some cross-over benefit, either local or systemic, has been suggested. For example, if the arch wire combines the whole maxillary/mandibular dentition as an integrate, the carry-across effect could reduce the difference in outcomes between strong and weak interventions (Lesaffre 2009; Needleman 2006).

Other studies have used a parallel design by randomly allocating one etching technique to each participant to eliminate this problem.

Furthermore, while the included studies achieved the required sample size, the original sample size calculations did not take into account clustering of brackets within the participants, modeling using other covariates or multiple testing issues. The use of clusters in these included studies reduces the power of the trial, and multiple testing increases the chance of false-positive results, so an increase in sample size is required (Kerry 1998). Future RCTs in orthodontics should take these issues into account and increase the sample size required accordingly (Manning 2006).

Although there was low heterogeneity in the studies that we metaanalyzed, further studies should consider the standardizing of study design in order to make results more comparable. This would involve factors such as the appliance system (e.g. self ligating or edgewise brackets systems), observation period (e.g. short or long term) and etching time (e.g. 15 or 30 seconds using $37 \%$ phosphoric acid), which may have been important confounders among the studies included.

With respect to the observation period, describing the bond failure rate over the whole period of a course of treatment in randomly allocated individuals is recommended. Previous studies have shown that most bond failures occur within the first three or six months after bracket placement (Aljubouri 2004; Hegarty 2002; O'Brien 1989). There may be three possible reasons for this increased failure rate during the first six months of treatment. First, any deficiencies in the bond strength of any individual bracket/ adhesive combination would become evident within this initial period of treatment. Second, the initial period of treatment is also a time of acclimatization and experimentation for recipients with regard to the type of food that can be tolerated by fixed orthodontic appliances. Finally, the initial phase of treatment may involve a period of overbite depression from heavy occlusal forces. Another study found that the failure rate for SEPs increased from $1.7 \%$ at six months to $7.0 \%$ at the completion of treatment, whereas that for a conventional system increased from $2.0 \%$ to $7.4 \%$; thus failure rates increased for both materials over the treatment period (Manning 2006). The authors of this study stated that describing bond failure rate over the whole period of a course of treatment in randomly allocated individuals could eliminate any variation due to treatment length. If participants are followed up over a set time period (e.g. one year), this may fail to reveal whether the performance of one material deteriorates over time. In addition, a systematic review of orthodontic bonding studies performed by the Cochrane Oral Health Group recommended that bonding studies follow all trial participants to the end of fixed appliance treatment (Mandall 2003). We also suggest that future studies follow this recommendation.

A potential confounder may be etching time. All the included studies used $37 \%$ phosphoric acid as the conventional etching system, but applied it for different times. The teeth were etched for 15 seconds in several studies (Aljubouri 2004; Asgari 2002; Banks 2007; Cal-Neto 2009; Ireland 2003; House 2006; Murfitt 2006) and for 30 seconds in others (Elekdag-Turk 2008a; Elekdag-Turk 2008b; Ghiz 2009; Manning 2006). Other previous studies have investigated the influence of different etching times on bracket bond failure rate, and the results indicated no significant difference in bond failure rate between groups using $37 \%$ phosphoric acid etching for 15 seconds versus either 30 seconds or 60 seconds (Carstensen 1986; Kinch 1988; Sadowsky 1990; Ye 2003). Furthermore, the manufacturer's instructions are sometimes not followed, making comparison with other reports inappropriate and difficult (dos Santos 2006). SEP (Transbond Plus) was applied for three to five seconds, according to the manufacturer's instructions, in several studies (Aljubouri 2004; Asgari 2002; Banks 2007; CalNeto 2009; Elekdag-Turk 2008a; Elekdag-Turk 2008b; Ghiz 2009; Ireland 2003; Manning 2006; Murfitt 2006). However, other studies have recommended application of the SEP for 10 to 15 seconds because the prolonged application time was reported to improve the bonding deficiency of self etch systems to enamel (Ferrari 1997; dos Santos 2006).

\section{Potential biases in the review process}

We have taken steps to limit bias during the process of undertaking this systematic review. We have made every effort to identify all relevant studies by searching seven databases, with no exlusions of any study due to language of publication. Nevertheless, it is possible that the databases searched do not cover all the published, unpublished and ongoing studies available, and this may have led to bias. Furthermore, we attempted to contact some of the study authors for missing information and clarification. Since the publication of the protocol, we have added an exclusion criterion (studies comparing different etchants or etching techniques but not reporting any orthodontic outcomes) and also decided that the objective outcomes in this review would not be affected by blinding. We acknowledge that such post-hoc 
changes could introduce bias but feel that they improve the quality, consistency and relevance of the review.

\section{Agreements and disagreements with other studies or reviews}

A recent systematic review compared SEPs with conventional etching and a meta-analysis of five studies indicated a higher bond failure rate for SEPs over 12 months (odds ratio 1.35 $95 \%$ confidence interval 0.99 to 1.83) (Fleming 2012). The 95\% confidence interval in the Fleming review was indicative of a more precise result than that obtained in our review, as the lower confidence limit implied only a slight chance that conventional etching was worse than etching using an SEP. Three of the studies in the meta-analysis were included in our meta-analysis (Aljubouri 2004; Banks 2007; Manning 2006). However, the Fleming review analyzed data at the tooth level. In agreement with the findings of our review, the Fleming review concluded that there was insufficient evidence to state whether there was a difference in demineralization between bonding techniques. The authors also concluded, however, that SEPs were associated with a slight but statistically significant time saving compared with conventional etching.

\section{AUTHORS' CONCLUSIONS}

\section{Implications for practice}

We found low-quality evidence that was insufficient to conclude whether or not there is a difference in bond failure rate between self etching primers (SEPs) and conventional etching systems when bonding fixed orthodontic appliances over 5- to 37-month followup. Due to the lack of sufficient numbers of randomized controlled trials (RCTs) and a lack of available statistical data, we were also unable to form any conclusions regarding the superiority of SEPs or conventional etching for the outcomes of decalcification, participant satisfaction or cost-effectiveness. For the same reasons, we were unable to form any conclusions regarding the superiority of any of the SEPs investigated over the others, or of any particular etching material (e.g. phosphoric acid, polyacrylic acid, maleic acid), concentration or etching time for the bonding of fixed orthodontic appliances.

\section{Implications for research}

More RCTs on this topic are required, especially studies investigating new etching techniques and etching materials. Future RCTs should report clearer and more uniform variables. In designing new clinical trials, the following need to be considered.

- E (Evidence): The present evidence was insufficient to help us to judge the advantages and disadvantages of different etchants or different etching techniques, and most of the studies could not provide data at participant level. In both parallel- and splitmouth-designed studies, it is important that data are analyzed at the participant level. Furthermore, reports on clinical trials would be improved by following the guidelines produced by the CONSORT Group to ensure that all relevant information is provided.

- $P$ (Population): Clear inclusion/exclusion criteria should be set. Type of malocclusion should be clearly described. Adults should be included in the trial to increase the generalizability of the results. More studies should be conducted in Africa, Eastern Asia and South America. A prior sample size calculation should be carried out, taking account of the clustering of teeth within the mouth.

- I (Intervention): More types or brands of new etching techniques and etching materials should be introduced to accelerate the development of this area.

- C (Comparison): Treatment regimens (e.g. appliance systems and observation periods), with the exception of the intervention, should be as similar as possible among trial participants and should be clearly described.

- O (Outcome): Decalcification, participant satisfaction and cost-effectiveness with different etchants or different etching techniques should be reported as important outcomes.

\section{ACK N O WLEDGEMENTS}

We would like to acknowledge the assistance of Anne Littlewood (Information Specialist, Cochrane Oral Health) in developing the search strategy and Helen Worthington (Cochrane Oral Health) in editing the review. We are grateful to the authors of some included studies (Banks 2007; Elekdag-Turk 2008a; Elekdag-Turk 2008b; Ghiz 2009; Manning 2006; Murfitt 2006) who replied to our emails and provided further information. 


\section{RE F E R E N C E S}

\section{References to studies included in this review}

Aljubouri 2004 \{published and unpublished data\}

Aljubouri YD, Millett DT, Gilmour WH. Six and 12 months' evaluation of a self-etching primer versus two-stage etch and prime for orthodontic bonding: a randomized clinical trial. European Journal of Orthodontics 2004;26(6):565-71.

\section{Asgari 2002 \{published data only\}}

Asgari S, Salas A, English J, Powers J. Clinical evaluation of bond failure rates with a new self-etching primer. Journal of Clinical Orthodontics 2002;36(12):687-9.

\section{Banks 2007 \{published and unpublished data\}}

Banks P, Thiruvenkatachari B. Long-term clinical evaluation of bracket failure with a self-etching primer: a randomized controlled trial. Journal of Orthodontics 2007;34(4):243-51.

\section{Cal-Neto 2009 \{published and unpublished data\}}

Cal-Neto JP, Quintao CA, Almeida MA, Miguel JA. Bond failure rates with a self-etching primer: a randomized controlled trial. American Journal of Orthodontics \& Dentofacial Orthopedics 2009;135(6):782-6.

\section{Elekdag-Turk 2008a \{published and unpublished data\}}

Elekdag-Turk S, Cakmak F, Isci D, Turk T. 12-month self-ligating bracket failure rate with a self-etching primer. The Angle Orthodontist 2008;78(6):1095-100.

\section{Elekdag-Turk 2008b \{published and unpublished data\}} Elekdag-Turk S, Isci D, Turk T, Cakmak F. Six-month bracket failure rate evaluation of a self-etching primer. European Journal of Orthodontics 2008;30(2):211-6.

\section{Ghiz 2009 \{published and unpublished data\}}

Ghiz MA, Ngan P, Kao E, Martin C, Gunel E. Effects of sealant and self-etching primer on enamel decalcification. Part II: an invivo study. American Journal of Orthodontics and Dentofacial Orthopedics 2009;135(2):206-13.

\section{House 2006 \{published and unpublished data\}} House K, Ireland AJ, Sherriff M. An investigation into the use of a single component self-etching primer adhesive system for orthodontic bonding: a randomized controlled clinical trial. Journal of Orthodontics 2006;33(1):38-44.

Ireland 2003 \{published and unpublished data\} Ireland AJ, Knight $\mathrm{H}$, Sherriff M. An in vivo investigation into bond failure rates with a new self-etching primer system. American Journal of Orthodontics and Dentofacial Orthopedics 2004;124(3):323-6.

\section{Manning 2006 \{published and unpublished data\}}

* Manning N, Chadwick SM, Plunkett D, Macfarlane TV. A randomized clinical trial comparing 'one-step' and 'twostep' orthodontic bonding systems. Journal of Orthodontics 2006;33(4):276-83.
Shah J, Chadwick S. Comparison of 1-stage orthodontic bonding systems and 2-stage bonding systems: a review of the literature and the results of a randomized clinical trial. L'Orthodontie Francaise 2009;80(2):167-78.

Murfitt 2006 \{published and unpublished data\}

Murfitt PG, Quick AN, Swain MV, Herbison GP. A randomised clinical trial to investigate bond failure rates using a self-etching primer. European Journal of Orthodontics 2006;28(5):444-9.

Noble 2006 \{published data only\}

Noble RR, Salas-Lopez A, English JD, Powers JM. Clinical evaluation of orthodontic self-etching primers. Texas Dental Journal 2006;123(3):274-8.

Paschos 2009 \{published and unpublished data\} Paschos E, Kurochkina N, Huth KC, Hansson CS, RudzkiJanson I. Failure rate of brackets bonded with antimicrobial and fluoride-releasing, self-etching primer and the effect on prevention of enamel demineralization. American Journal of Orthodontics and Dentofacial Orthopedics 2009;135(5):613-20.

\section{References to studies excluded from this review}

Amasyali 2011 \{published and unpublished data\}

Amasyali M, Enhos S, Uysal T, Saygun I, Kilic A, Bedir O. Effect of a self-etching adhesive containing an antibacterial monomer on clinical periodontal parameters and subgingival microbiologic composition in orthodontic patients. American Journal of Orthodontics and Dentofacial Orthopedics 2011;140(4):147-53.

\section{Artun 1984 \{published data only\}}

Artun J, Bergland S. Clinical trials with crystal growth conditioning as an alternative to acid-etch enamel pretreatment. American Journal of Orthodontics 1984;85(4):333-40.

\section{Cal-Neto 2005 \{published data only\}}

Cal-Neto JP, Miguel JA. An in vivo evaluation of bond failure rates with hydrophilic and self-etching primer systems. Journal of Clinical Orthodontics 2005;39(12):701-2.

dos Santos 2006 \{published and unpublished data\} dos Santos JE, Quioca J, Loguercio AD, Reis A. Six-month bracket survival with a self-etch adhesive. The Angle Orthodontist 2006;76(5):863-8.

Kinch 1988 \{published data only\}

Kinch AP, Taylor H, Warltier R, Oliver RG, Newcombe RG. A clinical trial comparing the failure rates of directly bonded brackets using etch times of 15 or 60 seconds. American Journal of Orthodontics and Dentofacial Orthopedics 1988;94(6):476-83.

LeCrone 2005 \{published data only\}

LeCrone V, Salas A, English J, Powers JM. Clinical evaluation of an orthodontic self-etching primer. Texas Dental Journal 2005;122(2):144-5. 
Miles 2008 \{published data only\}

Miles PG. Does microetching enamel reduce bracket failure when indirect bonding mandibular posterior teeth?. Australian Orthodontic Journal 2008;24(1):1-4.

\section{Pandis 2005 \{published data only\}}

Pandis N, Eliades T. A comparative in vivo assessment of the long-term failure rate of 2 self-etching primers. American Journal of Orthodontics and Dentofacial Orthopedics 2005;128(1):96-98

\section{Pandis 2006 \{published and unpublished data\}}

Pandis N, Polychronopoulou A, Eliades T. Failure rate of selfligating and edgewise brackets bonded with conventional acid etching and a self-etching primer: a prospective in vivo study. The Angle Orthodontist 2006;76(1):119-22.

Reis 2008 \{published and unpublished data\} Reis A, dos Santos JE, Loguercio AD, de Oliveira Bauer JR. Eighteen-month bracket survival rate: conventional versus self-etch adhesive. European Journal of Orthodontics 2008;30(1):94-9.

\section{Roberts-Harry 1992 \{published data only\}}

Roberts-Harry DP. Laser etching of teeth for orthodontic bracket placement: A preliminary clinical study. Lasers in Surgery and Medicine 1992;12(5):467-70.

\section{Sadowsky 1990 \{published and unpublished data\}}

Sadowsky PL, Retief DH, Cox PR, Hernandez Orsini R, Rape WG, Bradley EL. Effects of etchant concentration and duration on the retention of orthodontic brackets: an in vivo study. American Journal of Orthodontics and Dentofacial Orthopedics 1990;98(5):417-21.

\section{Additional references}

\section{Barkmeier 1994}

Barkmeier WW, Erickson RL. Shear bond strength of composite to enamel dentin using Scotchbond Multi-Purpose. American Journal of Dentistry 1994;7(3):175-9.

\section{Barkmeier 1995}

Barkmeier WW, Los SA, Triolo PT. Bond strengths and SEM evaluation of Clearfil Liner Bond 2. American Journal of Dentistry 1995;8(6):289-93.

\section{Begg 1994}

Begg CB, Mazumdar M. Operating characteristics of a rank correlation test for publication bias. Biometrics 1994;50(4):1088-101.

\section{Bishara 1993}

Bishara SE, Fehr DE, Jakobsen JR. A comparative study of the debonding strength of different ceramic brackets, enamel conditioners and adhesives. American Journal of Orthodontics and Dentofacial Orthopedics 1993;104(2):170-9.

\section{Bishara 1998}

Bishara SE, Gordan VV, VonWald L, Olson ME. Effect of an acidic primer on shear bond strength of orthodontic brackets. American Journal of Orthodontics and Dentofacial Orthopedics 1998;114(3):243-7.

\section{Bishara 2001}

Bishara SE, VonWald L, Laffoon JF, Warren JJ. Effect of a selfetch primer/adhesive on the shear bond strength of orthodontic brackets. American Journal of Orthodontics and Dentofacial Orthopedics 2001;119(6):621-4.

\section{Buonocore 1955}

Buonocore MG. A simple method of increasing the adhesion of acrylic filling materials to enamel surfaces. Journal of Dental Research 1955;34(6):849-53.

\section{Carstensen 1986}

Carstensen W. Clinical results after direct bonding of brackets using shorter etching times. American Journal of Orthodontics 1986;89(1):70-2.

\section{Egger 1997}

Egger M, Davey Smith G, Schneider M, Minder C. Bias in meta-analysis detected by a simple, graphical test. BMJ 1997;315(7109):629-34.

\section{Ferrari 1997}

Ferrari M, Mannocci F, Vichi A, Davidson CL. Effect of two etching times on the sealing ability of Clearfil Liner Bond 2 in Class $V$ restorations. American Journal of Dentistry 1997;10(2):66-70.

\section{Fleming 2012}

Fleming PS, Johal A, Pandis N. Self-etch primers and conventional acid-etch technique for orthodontic bonding: a systematic review and meta-analysis. American Journal of Orthodontics and Dentofacial Orthopedics 2012;142(1):83-94.

\section{Gorelick 1977}

Gorelick L. Bonding metal brackets with a self-polymerizing sealant-composite: a 12-month assessment. American Journal of Orthodontics 1977;71(5):541-53.

\section{GRADE 2004}

GRADE Working Group. Grading quality of evidence and strength of recommendations. BMJ 2004;328(7454):1490.

\section{Hegarty 2002}

Hegarty DJ, Macfarlane TV. In vivo bracket retention comparison of a resin-modified glass ionomer cement and a res-inbased bracket adhesive system after a year. American Journal of Orthodontics and Dentofacial Orthopedics 2002;121(5):496-501.

\section{Higgins 2011}

Higgins JPT, Green S (editors). Cochrane Handbook for Systematic Reviews of Interventions Version 5.1.0 [updated March 2011]. The Cochrane Collaboration, 2011. Available from www.cochrane-handbook.org. 


\section{Kerry 1998}

Kerry SM, Bland JM. Sample size in cluster randomisation. BMJ 1998;316:549.

\section{Kinch 1988}

Kinch AP, Taylor H, Warltier R, Oliver RG, Newcombe RG. A clinical trial comparing the failure rates of directly bonded brackets using etch times of 15 or 60 seconds. American Journal of Orthodontics and Dentofacial Orthopedics 1988;94(6):476-83.

\section{Lesaffre 2009}

Lesaffre E, Philstrom B, Needleman I, Worthington $\mathrm{H}$. The design and analysis of split-mouth studies: What statisticians and clinicians should know. Statistics in Medicine 2009;28:3470-3482.

\section{Mandall 2003}

Mandall NA, Hickman J, Macfarlane TV, Mattick RCR, Millett DT, Worthington HV. Adhesives for fixed orthodontic brackets. Cochrane Database of Systematic Reviews 2003, Issue 2. [DOI: 10.1002/14651858.CD002282]

\section{Needleman 2006}

Needleman I, Worthington HV, Giedrys-Leeper E, Tucker R. Guided tissue generation for periodontal infra-bony defects. Cochrane Database of Systematic Reviews 2006, Issue 2. [DOI: 10.1002/14651858.CD001724.pub2]

\section{Newman 1978}

Newman GV. Epoxy adhesives for orthodontic attachment progress report. American Journal of Orthodontics 1978;74:197.

\section{O'Brien 1989}

O'Brien KD, Read MJ, Sandison RJ, Roberts CT. A visible lightactivated direct-bonding material: an in vivo comparative study. American Journal of Orthodontics and Dentofacial Orthopedics 1989;95(4):348-51.

\section{O'Brien 1993}

O'Brien KD, Shwa WC, Roberts CT. The use of occlusal indices in assessing the provision of orthodontic treatment by the hospital orthodontic service of England and Wales. British Journal of Othodontics 1993;20(1):25-35.

\section{O'Reilly 1987}

O'Reilly MM, Featherstone JDB. Demineralization and remineralization around orthodontic appliances: an in vivo study. American Journal of Orthodontics and Dentofacial Orthopedics 1987;92:33-40.

\section{Ogaard 1988}

Ogaard B, Rolla G, Areudo J. Orthodontic appliances and enamel demineralization. Part 1. Lesion development. American Journal of Orthodontics and Dentofacial Orthopedics 1988;94:68-73.

\section{Olsen 1997}

Olsen ME, Bishara SE, Damon P, Jakobsen JR. Evaluation of Scotchbond Multipurpose and maleic acid as alternative methods of bonding orthodontic brackets. American Journal of Orthodontics and Dentofacial Orthopedics 1997;111(5):498-501.

\section{Retief 1973}

Retief DH. Effect of conditioning the enamel surface with phosphoric acid. Journal of Dental Research 1973;52(2):333-41.

\section{Richmond 1993}

Richmond S, Shaw WC, Stenphens CD, Webb WG, Roberts CT, Andrews M. Othondotics in the General Dental Service of England and Wales: a critical assessment of standards. British Dental Journal 1993;174(9):315-29.

\section{Ryan 2002}

Ryan WA, Edward CC, John HW. Bonding of stainless steel brackets to enamel with a new self-etching primer. American Journal of Orthodontics and Dentofacial Orthopedics 2002;122:274-6.

\section{Sadowsky 1976}

Sadowsky PL, Retief DH. A comparative study of some dental cements used in orthodontics. The Angle Orthodontist 1976;46(2):171-181.

\section{Silverstone 1974}

Silverstone LM. Fissure sealants. Caries Research 1974;8(1):2-26.

\section{Sunna 1998}

Sunna S, Rock WP. Clinical performance of orthodontic brackets and adhesive systems: a randomised clinical trial. British Journal of Orthodontics 1998;25(4):283-7.

\section{Triolo 1993}

Triolo PT Jr, Swift EJ Jr, Mudgil A, Levine A. Effects of etching time on enamel bond strengths. American Journal of Dentistry 1993;6(6):302-4.

\section{Ye 2003}

Ye L, Luo S, Bai J. The influence of different etch times on the failure rates of directly bonded brackets. Beijing Journal of Stomatology 2003;11(2):101-3.

\section{Zachrisson 1976}

Zachrisson BU. Cause and prevention of injuries to teeth and supporting structures during orthodontic treatment. American Journal of Orthodontics 1976;69(3):285-300.

\section{Zachrisson 1977}

Zachrisson BU. A posttreatment evaluation of direct bonding in orthodontics. American Journal of Orthodontics 1977;71:173.

* Indicates the major publication for the study 
CHARACTERISTICS OF STUDIES

Characteristics of included studies [ordered by study ID]

Aljubouri 2004

Study design: randomized controlled trial, split-mouth design
Time frame: not reported
Duration of the study: it took 12 months to finish the trial
Stratification: no
Sample size calculation: clearly mentioned
Setting: Unit of Orthodontics, Glasgow Dental Hospital and School, UK
Inclusion criteria: participants required upper and/or lower fixed appliance therapy with a preadjusted
edgewise system; incisors, canines and premolars fully erupted; good general health and oral hygiene
Exclusion criteria: enamel hypoplasia and existing enamel demineralization; cleft lip or palate, and
craniofacial syndromes; poor oral hygiene and/or poor periodontal health; gross or uncontrolled caries
Age: in total 51 participants, 32 younger than 15 years old (13 male, 19 female), 19 participants 15 years
or older (3 male, 16 female)
Sex: male 16, female 35
Participant type: 15 participants (6 male, 9 female) had class I malocclusion; 22 (7 male, 15 female) had
class $\mathbb{I}$ division 1 malocclusion; 3 (1 male, 2 female) had class II division 2 malocclusion; 11 ( 2 male, 9
female) had class $\mathbb{I I}$ malocclusion

Group 1: 389 brackets bonded with SEP (Transbond Plus SEP, 3M Unitek)

Group 2: 388 brackets bonded with conventional 2-stage etch and prime system (37\% phosphoric acid)

* 353 brackets bonded with each system were strictly paired - only these were used for the assessment of bracket bond failure rate

Outcomes

Primary: overall bond failure rate (the first 6 months, the second 6 months and the total 12 months of the trial); mean bond failure rate per participant (the first 6 months and the total 12 months of the trial)

Secondary: mean bracket bonding time per participant

Notes Funding: not mentioned

Author contact: further information was requested from the authors but there was no reply

\section{Risk of bias}

\section{Bias}

Random sequence genera- Low risk

tion (selection bias)

\section{Authors' judgement Support for judgement}

Quote: "with each subject randomly allocated to two bonding systems for each side of the mouth" and "the operator randomly allocated the upper right and lower left quadrants to be bonded with either the SEP or two-stage conventional etch and prime bonding system" and "Randomization was undertaken by opening a sealed envelope, prepared by the trial statistician, containing the treatment allocation"

Comment: done by a trial statistician, so we assume that it was done adequately 
Aljubouri 2004 (Continued)

Allocation concealment (selection bias)
Low risk Quote: "Randomization was undertaken by opening a sealed envelope, prepared by the trial statistician, containing the treatment allocation"

Comment: sealed envelopes by a trial statistician, so we assume that it was done adequately

$\begin{array}{ll}\begin{array}{l}\text { Blinding of participants } \\ \text { and personnel (perfor- }\end{array} & \begin{array}{l}\text { Quote: "The patient was not aware which bonding system (SEP or convention- } \\ \text { al two-stage bonding system) was used on each side of the mouth. It was not } \\ \text { possible to blind the operator to the type of bonding agent used, as the bond } \\ \text { All outcomes }\end{array} \\ \begin{array}{l}\text { ing technique differed between the two systems" } \\ \text { Comment: we do not consider that lack of operator blinding will have influ- } \\ \text { enced the outcomes }\end{array}\end{array}$

Blinding of outcome as- Low risk Comment: no blinding of outcome assessments. However, we do not consider sessment (detection bias) that lack of blinding will have influenced the outcomes
Quote: "No patient withdrew or dropped out of the trial over the 12 months observation period"

$\begin{array}{ll}\begin{array}{l}\text { Incomplete outcome data } \\ \text { (attrition bias) }\end{array} & \text { Low risk } \\ \text { All outcomes } & \text { observation period" }\end{array}$

All outcomes

Comment: outcomes were reported as stated in the 'Methods' section

\begin{tabular}{lll}
\hline $\begin{array}{l}\text { Selective reporting (re- } \\
\text { porting bias) }\end{array}$ & Low risk & Comment: outcomes were reported as stated in the 'Methods' section \\
\hline Other bias & Low risk & $\begin{array}{l}\text { Comment: we were unable to identify any other apparent sources of bias in the } \\
\text { study }\end{array}$
\end{tabular}

\section{Asgari 2002}

\begin{tabular}{|c|c|}
\hline \multirow[t]{5}{*}{ Methods } & Study design: randomized controlled trial, split-mouth design \\
\hline & Time frame: not reported \\
\hline & Duration of the study: not reported \\
\hline & Stratification: no \\
\hline & Sample size calculation: not mentioned \\
\hline \multirow[t]{7}{*}{ Participants } & Setting: Dental Branch, University of Texas, Houston, USA \\
\hline & Inclusion criteria: not mentioned \\
\hline & Exclusion criteria: not mentioned \\
\hline & Age: not mentioned \\
\hline & Sex: not mentioned \\
\hline & Participant type: not mentioned \\
\hline & Total recruited: 20 participants (348 brackets) \\
\hline \multirow[t]{2}{*}{ Interventions } & Group 1: 174 brackets bonded with SEP (Transbond Plus SEP, 3M Unitek) \\
\hline & Group 2: 174 brackets bonded with conventional 2-stage etch and prime system (37\% phosphoric acid) \\
\hline Outcomes & Primary: bond failure rate ( 6 months) \\
\hline
\end{tabular}


Asgari 2002 (Continued)

Notes $\quad$ Funding: not mentioned

Author contact: none

\section{Risk of bias}

\begin{tabular}{lll}
\hline Bias & Authors' judgement & Support for judgement \\
\hline $\begin{array}{l}\text { Random sequence genera- } \\
\text { tion (selection bias) }\end{array}$ & Unclear risk & $\begin{array}{l}\text { Quote: "One quadrant was randomly selected to receive the new self-etching } \\
\text { primer, along with the contralateral quadrant in the opposing arch" } \\
\text { Comment: insufficient information }\end{array}$ \\
\hline $\begin{array}{l}\text { Allocation concealment } \\
\text { (selection bias) }\end{array}$ & Unclear risk & $\begin{array}{l}\text { Comment: there is insufficient information in the report to establish whether } \\
\text { or not allocation was properly concealed }\end{array}$ \\
\hline
\end{tabular}

\begin{tabular}{ll}
\hline Blinding of participants & Low risk \\
and personnel (perfor- & $\begin{array}{l}\text { Comment: no blinding of participants and personnel. However, we do not con- } \\
\text { sider that lack of blinding will have influenced the outcomes }\end{array}$
\end{tabular}

mance bias)

All outcomes

\begin{tabular}{lll}
\hline $\begin{array}{l}\text { Blinding of outcome as- } \\
\text { sessment (detection bias) } \\
\text { All outcomes }\end{array}$ & Low risk & $\begin{array}{l}\text { Comment: no blinding of outcome assessments. However, we do not consider } \\
\text { that lack of blinding will have influenced the outcomes }\end{array}$ \\
\hline $\begin{array}{l}\text { Incomplete outcome data } \\
\text { (attrition bias) } \\
\text { All outcomes }\end{array}$ & Low risk & Comment: no participants were reported to have dropped out during the trial \\
\hline $\begin{array}{l}\text { Selective reporting (re- } \\
\text { porting bias) }\end{array}$ & High risk & $\begin{array}{l}\text { Comment: outcomes were reported as stated in the 'Methods' section but we } \\
\text { considered it inappropriate to report at tooth level rather than at participant } \\
\text { level }\end{array}$ \\
\hline $\begin{array}{l}\text { Other bias } \\
\text { Low risk }\end{array}$ & $\begin{array}{l}\text { Comment: we were unable to identify any other apparent sources of bias in the } \\
\text { study }\end{array}$ \\
\hline
\end{tabular}

Banks 2007

\begin{tabular}{l} 
Methods $\begin{array}{l}\text { Study design: randomized controlled trial, parallel-group design } \\
\text { Time frame: } 2003-2006 \\
\text { Duration of the study: it took } 5 \text { to } 37 \text { months to finish the trial } \\
\text { Stratification: no } \\
\text { Sample size calculation: clearly mentioned } \\
\text { Setting: UK district general hospital } \\
\text { Inclusion criteria: participants requiring (with no previous history of) fixed appliance therapy } \\
\text { Exclusion criteria: orthognathic cases; teeth with facial restorations or congenital enamel defects; sur- } \\
\text { gically exposed teeth and teeth where the bracket placement was delayed; craniofacial anomalies } \\
\text { Age: in total } 60 \text { participants, ranged from } 11 \text { years up to } 36 \text { years, } 22 \text { participants between } 11 \text { and } 13 \\
\text { years, } 33 \text { participants between } 14 \text { and } 16 \text { years, } 5 \text { participants } 17 \text { years or older } \\
\text { Sex: male } 23 \text {, female } 37\end{array}$ \\
\hline
\end{tabular}


Banks 2007 (Continued)

Participant type: 32 participants had class I malocclusion; 16 had class II division 1 malocclusion; 3 had class II division 2 malocclusion; 9 had class III malocclusion

\begin{tabular}{ll}
\hline Interventions & Group 1: 30 participants, 438 brackets bonded with SEP (Transbond Plus SEP, 3M Unitek) \\
& $\begin{array}{l}\text { Group 2: } 30 \text { participants, } 433 \text { brackets bonded with conventional etch and primer (37\% phosphoric } \\
\text { acid) }\end{array}$ \\
\hline Outcomes & $\begin{array}{l}\text { Primary: bracket adhesive failure rate (over the whole period of active treatment ranged from } 5 \text { to } 37 \\
\text { months) } \\
\text { Secondary: failure rates per subgroup; bonding time per bracket; adhesive remnant index }\end{array}$ \\
\hline Notes & Funding: not mentioned \\
Author contact: further information was requested from the authors and there was a reply
\end{tabular}

\section{Risk of bias}

\begin{tabular}{|c|c|c|}
\hline Bias & Authors' judgement & Support for judgement \\
\hline $\begin{array}{l}\text { Random sequence genera- } \\
\text { tion (selection bias) }\end{array}$ & Low risk & $\begin{array}{l}\text { Quote: "They were then randomized to either the control (AE) or experimental } \\
\text { (SEP) group. This was achieved by the operator preparing opaque numbered } \\
\text { sealed envelopes in blocks of } 10 \text { in advance, using random number tables" }\end{array}$ \\
\hline $\begin{array}{l}\text { Allocation concealment } \\
\text { (selection bias) }\end{array}$ & Low risk & $\begin{array}{l}\text { Quote: "This was achieved by the operator preparing opaque numbered } \\
\text { sealed envelopes in blocks of } 10 \text { in advance, using random number tables" }\end{array}$ \\
\hline $\begin{array}{l}\text { Blinding of participants } \\
\text { and personnel (perfor- } \\
\text { mance bias) } \\
\text { All outcomes }\end{array}$ & Low risk & $\begin{array}{l}\text { Comment: no blinding of participants and personnel. However, we do not con- } \\
\text { sider that lack of blinding will have influenced the outcomes }\end{array}$ \\
\hline $\begin{array}{l}\text { Blinding of outcome as- } \\
\text { sessment (detection bias) } \\
\text { All outcomes }\end{array}$ & Low risk & $\begin{array}{l}\text { Comment: no blinding of outcome assessments. However, we do not consider } \\
\text { that lack of blinding will have influenced the outcomes }\end{array}$ \\
\hline $\begin{array}{l}\text { Incomplete outcome data } \\
\text { (attrition bias) } \\
\text { All outcomes }\end{array}$ & Low risk & $\begin{array}{l}\text { Quote: "All patients were followed to the end or discontinuation of treatment" } \\
\text { and "One participant from each group failed to re-attend during treatment and } \\
\text { was lost from the study. Data were obtained for the remaining } 60 \text { ( } 30 \text { from each } \\
\text { group)" } \\
\text { Comment: no reasons given for drop-outs but there were no adverse events in } \\
\text { either group }\end{array}$ \\
\hline $\begin{array}{l}\text { Selective reporting (re- } \\
\text { porting bias) }\end{array}$ & Low risk & Comment: outcomes were reported as stated in the 'Methods' section \\
\hline Other bias & Low risk & $\begin{array}{l}\text { Comment: we were unable to identify any other apparent sources of bias in the } \\
\text { study }\end{array}$ \\
\hline
\end{tabular}

Cal-Neto 2009

Study design: randomized controlled trial, parallel-group design
Time frame: not reported
Duration of the study: it took 12 months to finish the trial


Cal-Neto 2009 (Continued)

Stratification: no

Sample size calculation: clearly mentioned

Participants Setting: Department of Orthodontics, School of Dentistry, State University of Rio de Janeiro, Rio de Janeiro, Brazil

Inclusion criteria: required 2-arch fixed therapy; no caries, fillings or hypoplasia; no occlusal interferences to eliminate the influence of trauma on failure rate

Exclusion criteria: enamel hypoplasia and existing enamel demineralization; cleft lip or palate and craniofacial syndromes

Age: in total 28 participants, 12 between 11 and 13 years; 9 between 14 and 16 years; 7 over 17 years; mean age 14 years 11 months

Sex: male 11 (SEP 6, conventional 5), female 17 (SEP 8, conventional 9)

Participant type: not mentioned

\begin{tabular}{ll}
\hline Interventions & Group 1: 14 participants (276 brackets) bonded with SEP (Transbond Plus SEP, 3M Unitek) \\
& $\begin{array}{l}\text { Group 2: } 14 \text { participants (271 brackets) bonded with conventional multistep system (37\% phosphoric } \\
\text { acid) }\end{array}$ \\
\hline Outcomes & Primary: bond failure rate (12 months) \\
& $\begin{array}{l}\text { Secondary: bracket survival distributions with respect to bonding procedure, dental arch, type of tooth } \\
\text { and participant sex }\end{array}$ \\
\hline Notes & Funding: not mentioned \\
& Author contact: further information was requested from the authors but there was no reply
\end{tabular}

\section{Risk of bias}

\begin{tabular}{lll}
\hline Bias & Authors' judgement & Support for judgement \\
\hline $\begin{array}{ll}\text { Random sequence genera- } \\
\text { tion (selection bias) }\end{array}$ & Unclear risk & $\begin{array}{l}\text { Quote: "They were randomly allocated with opaque numbered sealed en- } \\
\text { velopes (blocked randomization ensured equal numbers of patients in each } \\
\text { group after every tenth subject) to either the TBXT or the SEP group" }\end{array}$ \\
& $\begin{array}{l}\text { Comment: possibly done, but the details of the blocked randomization were } \\
\text { not clear }\end{array}$
\end{tabular}

\begin{tabular}{|c|c|c|}
\hline $\begin{array}{l}\text { Allocation concealment } \\
\text { (selection bias) }\end{array}$ & Low risk & $\begin{array}{l}\text { Quote: "They were randomly allocated with opaque numbered sealed en- } \\
\text { velopes to either the TBXT or the SEP group" }\end{array}$ \\
\hline $\begin{array}{l}\text { Blinding of participants } \\
\text { and personnel (perfor- } \\
\text { mance bias) } \\
\text { All outcomes }\end{array}$ & Low risk & $\begin{array}{l}\text { Comment: no blinding of participants and personnel. However, we do not con- } \\
\text { sider that lack of blinding will have influenced the outcomes }\end{array}$ \\
\hline $\begin{array}{l}\text { Blinding of outcome as- } \\
\text { sessment (detection bias) } \\
\text { All outcomes }\end{array}$ & Low risk & $\begin{array}{l}\text { Comment: not mentioned. However, we do not consider that lack of blinding } \\
\text { will have influenced the outcomes }\end{array}$ \\
\hline $\begin{array}{l}\text { Incomplete outcome data } \\
\text { (attrition bias) } \\
\text { All outcomes }\end{array}$ & Low risk & $\begin{array}{l}\text { Quote: "There were } 15 \text { patients in each group, but } 2 \text { patients moved and were } \\
\text { removed from the study ( } 1 \text { from each group). Thus, there were } 14 \text { patients in } \\
\text { each group" }\end{array}$ \\
\hline
\end{tabular}


Cal-Neto 2009 (Continued)

Selective reporting (re- High risk Comment: outcomes were reported as stated in the 'Methods' section but we porting bias) considered it inappropriate to report at tooth level rather than at participant level

$\begin{array}{ll}\text { Other bias } \quad \text { Low risk } & \begin{array}{l}\text { Comment: we were unable to identify any other apparent sources of bias in the } \\ \text { study }\end{array}\end{array}$

\section{Elekdag-Turk 2008a}

Study design: randomized controlled trial, split-mouth design
Time frame: not reported
Duration of the study: it took 12 months to finish the trial
Stratification: no
Sample size calculation: not clearly mentioned in the trial, and from contact with the author we know
that they did not calculate the sample size, but used some literature as a guideline for sample size de-
termination

Participants Setting: Department of Orthodontics, Faculty of Dentistry, University of Ondokuz Mayis, Samsun, Turkey

Inclusion criteria: participants required 2-arch fixed appliance therapy; extraction participants were included if their extractions were balanced; no hypoplasia or restorations on the buccal surfaces of the teeth

Exclusion criteria: open bites or class III malocclusions

Age: in total 39 participants, 3 younger than 12 years old; 10 between 12 and 13 years; 14 between 14 and 15 years; 6 between 16 and 18 years; 6 over 18 years; mean age 15 years 7 months

Sex: male 8 , female 31

Participant type: no restriction concerning type of malocclusion, except exclusion of open bite or class III

Interventions Group 1: 344 brackets bonded with SEP (Transbond Plus SEP, 3M Unitek)

Group 2: 344 brackets bonded with conventional 2-step etch and prime method (37\% phosphoric acid)

Outcomes Primary: bond failure rate (the first 6 months, the second 6 months, and the total 12 months of the trial)

Secondary: bracket survival distributions with respect to bonding procedure, dental arch, type of tooth and participant sex; adhesive remnant index

Notes Funding: not mentioned

Author contact: further information was requested from the authors and there was a reply

\section{Risk of bias}

\begin{tabular}{lll}
\hline Bias & Authors' judgement & Support for judgement \\
\hline $\begin{array}{ll}\text { Random sequence genera- } \\
\text { tion (selection bias) }\end{array}$ & High risk & $\begin{array}{l}\text { Quote: "Bonding procedures were allocated by the split-mouth method. Each } \\
\text { patient's mouth was divided into quadrants, and a contralateral bonding pat- } \\
\text { tern was randomly alternated from patient to patient to ensure an equal distri- } \\
\text { bution of enamel treatments between the right and left sides" }\end{array}$
\end{tabular}


Elekdag-Turk 2008a (Continued)

Comment: we contacted the author who mentioned that the allocation of the bonding method was determined by coin tossing for the first participant, and then alternation afterwards

\begin{tabular}{ll}
\hline $\begin{array}{l}\text { Allocation concealment } \\
\text { (selection bias) }\end{array}$ & Comment: not mentioned in the trial. However, from contact with the author, \\
& we know that the orthodontist who bonded the brackets knew about the allo- \\
cation (alternation) and after the bonding procedure these participants were & handed over for treatment to the other orthodontist taking part in these stud- \\
& ies
\end{tabular}

Blinding of participants Low risk Comment: not mentioned in the trial. However, we do not consider that lack of and personnel (perfor- blinding will have influenced the outcomes

mance bias)

All outcomes

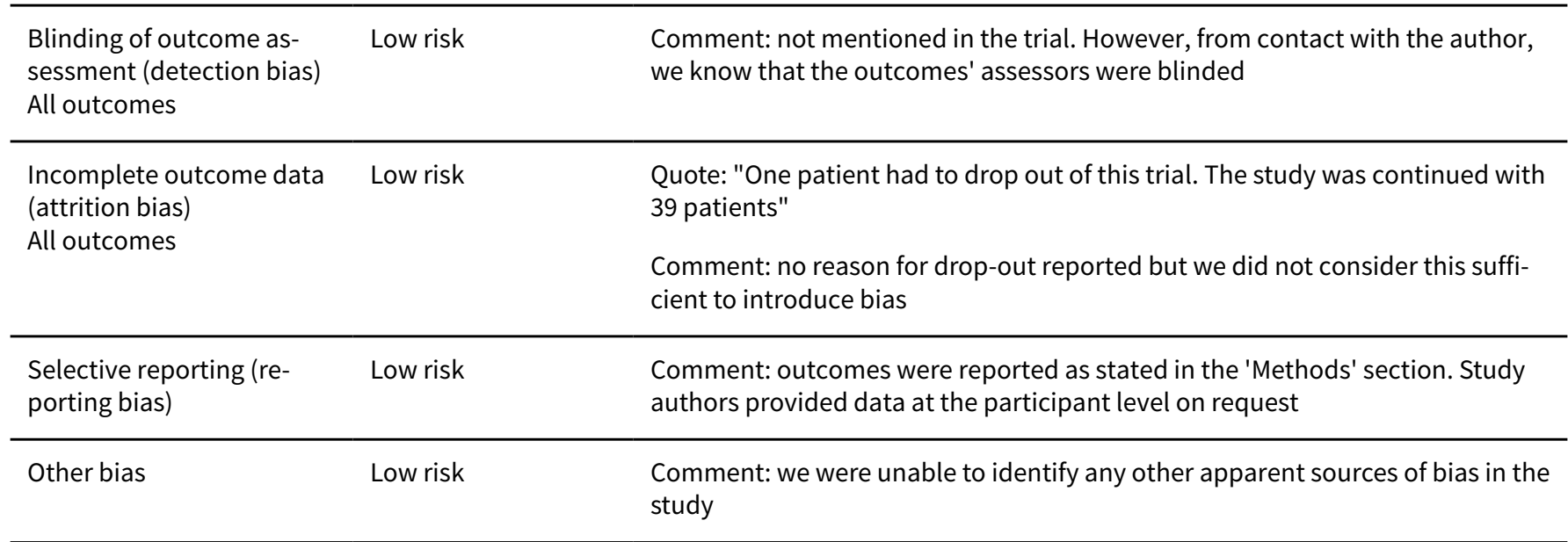

\title{
Elekdag-Turk 2008b
}

Study design: randomized controlled trial, split-mouth design
Time frame: not reported
Duration of the study: it took 6 months to finish the trial
Stratification: no

Sample size calculation: not clearly mentioned in the trial, and from contact with the author we know that they did not calculate the sample size, but used some literature as a guideline for sample size determination

Participants

\author{
Setting: Department of Orthodontics, Faculty of Dentistry, University of Ondokuz Mayis, Samsun, \\ Turkey \\ Inclusion criteria: participants required 2-arch fixed appliance therapy; extraction participants were in- \\ cluded if their extractions were balanced; no hypoplasia or restorations on the buccal surfaces of the \\ teeth \\ Exclusion criteria: skeletal class III malocclusion
}

Age: in total 37 participants, 3 younger than 12 years old; 5 between 12 and 13 years; 7 between 14 and 15 years; 11 between 16 and 18 years; 11 over 18 years; mean age 16 years 5 months

Sex: male 14, female 23 
Elekdag-Turk 2008b (Continued)

Participant type: no restriction concerning the type of malocclusion, except exclusion of skeletal class III

\begin{tabular}{ll}
\hline Interventions & Group 1: 336 brackets bonded with SEP (Transbond Plus SEP, 3M Unitek) \\
Group 2: 336 brackets bonded with conventional 2-step etch and prime method (37\% phosphoric acid)
\end{tabular}

Primary: bond failure rate (6 months)
Secondary: bracket survival distributions with respect to bonding procedure, dental arch, type of tooth
and participant sex; mean bracket bonding time; adhesive remnant index

Notes Funding: not mentioned

Author contact: further information was requested from the authors and there was a reply

\section{Risk of bias}

Bias Authors' judgement Support for judgement

Random sequence genera- High risk tion (selection bias)

Quote: "Bonding procedures were allocated by the split-mouth method. Each patient's mouth was divided into quadrants, and a contralateral bonding pattern was randomly alternated from patient to patient to ensure an equal distribution of enamel treatments between the right and left sides"

Comment: we contacted the author who mentioned that the allocation of the bonding method was determined by coin tossing for the first participant, and then alternation afterwards

\begin{tabular}{ll}
\hline $\begin{array}{l}\text { Allocation concealment } \\
\text { (selection bias) }\end{array}$ & $\begin{array}{l}\text { Comment: not mentioned in the trial. However, from contact with the author, } \\
\text { we know that the orthodontist who bonded the brackets knew about the allo- } \\
\text { cation (alternation) and after the bonding procedure these participants were } \\
\text { handed over for treatment to the other orthodontist taking part in these stud- } \\
\text { ies }\end{array}$
\end{tabular}

Blinding of participants Low risk Comment: not mentioned in the trial. However, we do not consider that lack of
and personnel (perfor- blinding will have influenced the outcomes

mance bias)

All outcomes

\begin{tabular}{|c|c|c|}
\hline $\begin{array}{l}\text { Blinding of outcome as- } \\
\text { sessment (detection bias) } \\
\text { All outcomes }\end{array}$ & Low risk & $\begin{array}{l}\text { Comment: not mentioned in the trial. However, from contact with the author, } \\
\text { we know that the outcomes assessors were blinded }\end{array}$ \\
\hline $\begin{array}{l}\text { Incomplete outcome data } \\
\text { (attrition bias) } \\
\text { All outcomes }\end{array}$ & Low risk & Comment: no participants were reported to have dropped out during the trial \\
\hline $\begin{array}{l}\text { Selective reporting (re- } \\
\text { porting bias) }\end{array}$ & Low risk & $\begin{array}{l}\text { Comment: outcomes were reported as stated in the 'Methods' section. Study } \\
\text { authors provided data at the participant level on request }\end{array}$ \\
\hline Other bias & Low risk & $\begin{array}{l}\text { Comment: we were unable to identify any other apparent sources of bias in the } \\
\text { study }\end{array}$ \\
\hline
\end{tabular}

Ghiz 2009

Methods Study design: randomized controlled trial, split-mouth design

Enamel etching for bonding fixed orthodontic braces (Review) 
Ghiz 2009 (Continued)

Time frame: not reported

Duration of the study: 18 to 24 months

Stratification: no

Sample size calculation: not clearly mentioned in the trial, and from contact with the author, we know that they did a power analysis from previous studies

Participants

Setting: Department of Orthodontics, West Virginia University School of Dentistry, Morgantown, USA

Inclusion criteria: (1) permanent dentition in both arches; (2) no previous orthodontic treatment; (3) comprehensive orthodontic treatment, with fixed appliances, planned to be completed between 18 and 24 months; and (4) no detectable decalcification on the surface of the tooth to be bonded in the maxillary and mandibular dentition

Exclusion criteria: not clearly mentioned

Age: not mentioned

Sex: not mentioned

Participant type: not mentioned

Total recruited: 25 participants (469 teeth)

Interventions

Group 1: 236 brackets bonded with SEP (Transbond Plus SEP, 3M Unitek)

Group 2: 233 brackets bonded with conventional etch and sealant (37\% phosphoric acid)

\begin{tabular}{ll}
\hline Outcomes & Enamel decalcification; oral hygiene compliance \\
\hline Notes & Funding: not mentioned \\
& Author contact: further information was requested from the authors and there was a reply \\
\hline
\end{tabular}

\section{Risk of bias}

\begin{tabular}{lll}
\hline Bias & Authors' judgement & Support for judgement \\
\hline $\begin{array}{l}\text { Random sequence genera- } \\
\text { tion (selection bias) }\end{array}$ & Low risk & $\begin{array}{l}\text { Quote: "The patients were randomly assigned to have the CES used on } 1 \text { arc } \\
\text { and the SEP on the other arch" }\end{array}$ \\
& $\begin{array}{l}\text { Comment: from contact with the author, we know that randomization was } \\
\text { done by the operator using the flip of a coin }\end{array}$
\end{tabular}

\begin{tabular}{|c|c|c|}
\hline $\begin{array}{l}\text { Allocation concealment } \\
\text { (selection bias) }\end{array}$ & Unclear risk & $\begin{array}{l}\text { Comment: there is insufficient information in the report to establish whether } \\
\text { or not allocation was properly concealed }\end{array}$ \\
\hline
\end{tabular}

\begin{tabular}{ll}
\hline $\begin{array}{l}\text { Blinding of participants } \\
\text { and personnel (perfor- } \\
\text { mance bias) }\end{array}$ & $\begin{array}{l}\text { Comment: unclear in the report - the outcomes in this study are more subjec- } \\
\text { tive than the primary outcome of the review (bond failure rate) }\end{array}$ \\
All outcomes & \\
\hline
\end{tabular}

\begin{tabular}{lll}
\hline $\begin{array}{l}\text { Blinding of outcome as- } \\
\text { sessment (detection bias) } \\
\text { All outcomes }\end{array}$ & Unclear risk & $\begin{array}{l}\text { Comment: unclear in the report - the outcomes in this study are more subjec- } \\
\text { tive than the primary outcome of the review (bond failure rate) }\end{array}$ \\
\hline $\begin{array}{l}\text { Incomplete outcome data } \\
\begin{array}{l}\text { (attrition bias) } \\
\text { All outcomes }\end{array}\end{array}$ & Low risk & Comment: no participants were reported to have dropped out during the trial \\
\hline
\end{tabular}


Ghiz 2009 (Continued)

Selective reporting (re- High risk Comment: outcomes were reported as stated in the 'Methods' section but we porting bias) considered it inappropriate to report at tooth level rather than at participant level

$\begin{array}{ll}\text { Other bias } \quad \text { Low risk } & \begin{array}{l}\text { Comment: we were unable to identify any other apparent sources of bias in the } \\ \text { study }\end{array}\end{array}$

\section{House 2006}

Methods

Study design: randomized controlled trial, split-mouth design

Time frame: not reported

Duration of the study: it took 12 months to finish the trial

Stratification: no

Sample size calculation: clearly mentioned

\section{Participants}

Setting: Orthodontic Department, Bristol Dental School, UK

Inclusion criteria: participants receiving only metal brackets on upper and lower arches; bands to be placed on molar teeth only; no restorations that would preclude bonding to enamel

Exclusion criteria: not clearly mentioned

Age: not mentioned

Sex: not mentioned

Participant type: not clearly mentioned

Total recruited: 20 participants (339 brackets)

Interventions

Group 1: 170 brackets bonded with SEP (Ideal 1 SEP, GAC Orthodontic Products)

Group 2: 169 brackets bonded with conventional acid etching system (37\% phosphoric acid)

Outcomes Primary: bond failure rate (at 1, 6 and 12 months after placement)

Secondary: adhesive remnant index

Notes

Funding: not mentioned

Author contact: further information was requested from the authors but there was no reply

\section{Risk of bias}

\begin{tabular}{lll}
\hline Bias & Authors' judgement & Support for judgement \\
\hline $\begin{array}{l}\text { Random sequence genera- } \\
\text { tion (selection bias) }\end{array}$ & Low risk & $\begin{array}{l}\text { Quote: "Patients were not informed as to which were the experimental and } \\
\text { control quadrants, and randomization was achieved by using random num- } \\
\text { bers from a random number table and a system of sealed envelopes" }\end{array}$ \\
\hline $\begin{array}{l}\text { Allocation concealment } \\
\text { (selection bias) }\end{array}$ & Low risk & $\begin{array}{l}\text { Quote: "randomization was achieved by using random numbers from a ran- } \\
\text { dom number table and a system of sealed envelopes" }\end{array}$ \\
& Comment: probably done \\
\hline
\end{tabular}


House 2006 (Continued)

Blinding of participants Low risk Quote: "Patients were not informed as to which were the experimental and and personnel (performance bias)

All outcomes

control quadrants"

Quote: "The bonding protocol for each patient followed a contralateral pattern to eliminate operator bias"

Comment: even if blinding was broken, we do not consider that lack of blinding will have influenced the outcomes

\begin{tabular}{|c|c|c|}
\hline $\begin{array}{l}\text { Blinding of outcome as- } \\
\text { sessment (detection bias) } \\
\text { All outcomes }\end{array}$ & Low risk & $\begin{array}{l}\text { Comment: not mentioned. However, we do not consider that lack of blinding } \\
\text { will have influenced the outcomes }\end{array}$ \\
\hline $\begin{array}{l}\text { Incomplete outcome data } \\
\text { (attrition bias) } \\
\text { All outcomes }\end{array}$ & Low risk & $\begin{array}{l}\text { Quote: "No patients were lost to follow-up during this trial. However, due to } \\
\text { the large number of bond failures noticed early on in the study, patient recruit- } \\
\text { ment was stopped prematurely and in total only } 20 \text { patients, rather than the } \\
\text { planned } 30 \text { patients were recruited into the study" }\end{array}$ \\
\hline $\begin{array}{l}\text { Selective reporting (re- } \\
\text { porting bias) }\end{array}$ & High risk & $\begin{array}{l}\text { Comment: outcomes were reported as stated in the 'Methods' section but we } \\
\text { considered it inappropriate to report at tooth level rather than at participant } \\
\text { level }\end{array}$ \\
\hline Other bias & Low risk & $\begin{array}{l}\text { Comment: we were unable to identify any other apparent sources of bias in the } \\
\text { study }\end{array}$ \\
\hline
\end{tabular}

Ireland 2003

Study design: randomized controlled trial, split-mouth design
Time frame: not reported
Duration of the study: it took 6 months to finish the trial
Stratification: no
Sample size calculation: not clearly mentioned

Participants Setting: Orthodontic Department of the Royal United Hospital, Bath, UK

Inclusion criteria: participants required maxillary and mandibular fixed appliances with no crowns, bridges or veneers anterior to the first permanent molars; both extraction and non-extraction participants participated, extraction participants were included if their extractions were balanced

Exclusion criteria: not clearly mentioned

Age: not mentioned

Sex: not mentioned

Participant type: both extraction and non-extraction participants participated, extraction participants were included if their extractions were balanced

Total recruited: 20 participants (364 brackets)

Interventions Group 1: 182 brackets bonded with SEP (Transbond Plus SEP, 3M Unitek)

Group 2: 182 brackets bonded with conventional acid etching system (37\% phosphoric acid) 
Ireland 2003 (Continued)
Notes
Funding: not mentioned
Author contact: further information was requested from the authors but there was no reply

\section{Risk of bias}

\begin{tabular}{|c|c|c|}
\hline Bias & Authors' judgement & Support for judgement \\
\hline $\begin{array}{l}\text { Random sequence genera- } \\
\text { tion (selection bias) }\end{array}$ & Low risk & $\begin{array}{l}\text { Quote: "Once entered into the study, each subject was randomly assigned a } \\
\text { number by a random number table; this determined which quadrants were al- } \\
\text { located to which pretreatment" }\end{array}$ \\
\hline $\begin{array}{l}\text { Allocation concealment } \\
\text { (selection bias) }\end{array}$ & Unclear risk & $\begin{array}{l}\text { Comment: there is insufficient information in the report to establish whether } \\
\text { or not allocation was properly concealed }\end{array}$ \\
\hline $\begin{array}{l}\text { Blinding of participants } \\
\text { and personnel (perfor- } \\
\text { mance bias) } \\
\text { All outcomes }\end{array}$ & Low risk & $\begin{array}{l}\text { Comment: not mentioned. However, we do not consider that lack of blinding } \\
\text { will have influenced the outcomes }\end{array}$ \\
\hline $\begin{array}{l}\text { Blinding of outcome as- } \\
\text { sessment (detection bias) } \\
\text { All outcomes }\end{array}$ & Low risk & $\begin{array}{l}\text { Comment: not mentioned. However, we do not consider that lack of blinding } \\
\text { will have influenced the outcomes }\end{array}$ \\
\hline $\begin{array}{l}\text { Incomplete outcome data } \\
\text { (attrition bias) } \\
\text { All outcomes }\end{array}$ & Low risk & Comment: no participants were reported to have dropped out during the trial \\
\hline $\begin{array}{l}\text { Selective reporting (re- } \\
\text { porting bias) }\end{array}$ & High risk & $\begin{array}{l}\text { Comment: outcomes were reported as stated in the 'Methods' section but we } \\
\text { considered it inappropriate to report at tooth level rather than at participant } \\
\text { level }\end{array}$ \\
\hline Other bias & Low risk & $\begin{array}{l}\text { Comment: we were unable to identify any other apparent sources of bias in the } \\
\text { study }\end{array}$ \\
\hline
\end{tabular}

Manning 2006

\section{Methods}

Study design: randomized controlled trial, parallel-group design

Time frame: not reported

Duration of the study: the duration of follow-up ranged from 216 days to 1157 days

Stratification: no

Sample size calculation: clearly mentioned

Setting: NHS Hospital Orthodontic Department, Chester, UK
Inclusion criteria: all participants required fixed orthodontic therapy and no effort was made to match
the participants for age, sex or malocclusion to ensure a representative range of orthodontic individu-
als
Exclusion criteria: individuals requiring single arch treatments or orthognathic surgery as part of their
orthodontic treatment


Age: in total 34 participants, 1 participants was 11 years old; 5 participants were 12 years old; 7 participants were 13 years old; 10 participants were 14 years old; 9 participants were 15 years old; 2 participants were 16 years old

Sex: male 11 (4 with SEP, 7 with conventional group), female 23 (13 with SEP, 10 with conventional group)

Participant type: not mentioned

Interventions $\quad$ Group 1: 17 participants (299 brackets) bonded with SEP (Transbond Plus SEP, 3M Unitek)
Group 2: 17 participants (298 brackets) bonded with conventional acid etching system (37\% phosphor-
ic acid)

Outcomes Primary: overall bond failure rate (at 6 months, 12 months and at completion of treatment); mean bond failure rate per participant (at completion of treatment)

Secondary: bracket failure rates with respect to operator, participant and tooth bonded

$\begin{array}{ll}\text { Notes } & \text { Funding: not mentioned } \\ & \text { Author contact: further information was requested from the authors and there was a reply }\end{array}$

\section{Risk of bias}

\begin{tabular}{lll}
\hline Bias & Authors' judgement & Support for judgement \\
\hline $\begin{array}{l}\text { Random sequence genera- } \\
\text { tion (selection bias) }\end{array}$ & Low risk & $\begin{array}{l}\text { Quote: "Patients were consented (no information was available on con- } \\
\text { sent rate) and randomly allocated (using random number tables, controlled } \\
\text { with permuted blocks to ensure equal numbers of patients in each group af- } \\
\text { ter every sixth subject) to either a conventional (two-stage) adhesive group } \\
\text { (Transbond 'TB') or alternatively to the (one-stage) self-etching primer adhe- } \\
\text { sive group ('SEP')" } \\
\text { Comment: the author mentioned that the random number table was pro- } \\
\text { duced by the trial statistician }\end{array}$ \\
\end{tabular}

\begin{tabular}{|c|c|c|}
\hline $\begin{array}{l}\text { Allocation concealment } \\
\text { (selection bias) }\end{array}$ & Unclear risk & $\begin{array}{l}\text { Comment: there is insufficient information in the report to establish whether } \\
\text { or not allocation was properly concealed }\end{array}$ \\
\hline $\begin{array}{l}\text { Blinding of participants } \\
\text { and personnel (perfor- } \\
\text { mance bias) } \\
\text { All outcomes }\end{array}$ & Low risk & $\begin{array}{l}\text { Comment: not mentioned in the trial. Nevertheless, after contact with the au- } \\
\text { thor, we know that there was no blinding; however, personnel had equipoise } \\
\text { (i.e. all operators felt confident both techniques were equally valid and did not } \\
\text { know which would have the 'best' outcome) }\end{array}$ \\
\hline $\begin{array}{l}\text { Blinding of outcome as- } \\
\text { sessment (detection bias) } \\
\text { All outcomes }\end{array}$ & Low risk & $\begin{array}{l}\text { Comment: no blinding of outcome assessments. However, we do not consider } \\
\text { that lack of blinding will have influenced the outcomes }\end{array}$ \\
\hline $\begin{array}{l}\text { Incomplete outcome data } \\
\text { (attrition bias) } \\
\text { All outcomes }\end{array}$ & Low risk & $\begin{array}{l}\text { Quote: "There were } 18 \text { patients in the SEP group, } 17 \text { patients in the TB group, } \\
\text { but one patient in the SEP group was lost to follow-up (the patient moved } \\
\text { away from the area and was removed from the study). This meant there were } \\
17 \text { patients in each group" }\end{array}$ \\
\hline $\begin{array}{l}\text { Selective reporting (re- } \\
\text { porting bias) }\end{array}$ & Low risk & Comment: outcomes were reported as stated in the 'Methods' section \\
\hline Other bias & Low risk & $\begin{array}{l}\text { Comment: we were unable to identify any other apparent sources of bias in the } \\
\text { study }\end{array}$ \\
\hline
\end{tabular}


Murfitt 2006

Study design: randomized controlled trial, split-mouth design
Time frame: between September 2002 and June 2003
Duration of the study: it took 12 months to finish the trial
Stratification: no
Sample size calculation: clearly mentioned

Setting: Orthodontic Clinic of the University of Otago School of Dentistry, New Zealand
Inclusion criteria: all participants required 1 or 2-arch fixed appliance therapy, and did not have any
gross enamel defects which could affect bracket bond strength
Exclusion criteria: not clearly mentioned

Age: in total 39 participants, 2 younger than 12 years old; 17 between 12 and 13 years; 16 between 14 and 15 years; 4 over 16 years; mean age was 14.4 years, $S D=2.5$ years

Sex: male 13 , female 26

Participant type: the authors did not record the type of malocclusion but participants had a cross-section of malocclusions which required conventional edgewise treatment - this may have been carried out non-extraction or with premolar extractions

Interventions Group 1: 331 brackets bonded with SEP (Transbond Plus SEP, 3M Unitek)

Group 2: 330 brackets bonded with conventional acid etching system (37\% phosphoric acid)

\begin{tabular}{ll}
\hline Outcomes & Primary: bond failure rate (12 months) \\
& $\begin{array}{l}\text { Secondary: failure and survival rates with respect to age and gender of participants, each etching sys- } \\
\text { tem, operator, mode of failure, tooth position in the dental arch and number of manipulations prior to } \\
\text { curing the adhesive; adhesive remnant index }\end{array}$ \\
\hline Notes & Funding: not mentioned \\
& Author contact: further information was requested from the authors and there was a reply
\end{tabular}

\section{Risk of bias}

\begin{tabular}{lll}
\hline Bias & Authors' judgement & Support for judgement \\
\hline $\begin{array}{l}\text { Random sequence genera- } \\
\text { tion (selection bias) }\end{array}$ & Low risk & $\begin{array}{l}\text { Quote: "The patients were randomly assigned to one of two operators... A } \\
\text { split-mouth, cross-quadrant design (Glavind, 1977) was used to determine } \\
\text { which etching and primer systems were applied in each quadrant. Random- } \\
\text { ization for allocation of either of the two etch and primer systems to the upper } \\
\text { right quadrant was undertaken using a block randomization method as de- } \\
\text { scribed by Roberts and Torgerson (1998)" }\end{array}$ \\
&
\end{tabular}

$\begin{array}{ll}\begin{array}{l}\text { Allocation concealment } \\ \text { (selection bias) }\end{array} & \text { Low risk } \\ \text { entered into the trial" }\end{array}$

Comment: from contact with the author, we know that allocation concealment was achieved through the use of sealed envelopes

\begin{tabular}{|c|c|c|}
\hline $\begin{array}{l}\text { Blinding of participants } \\
\text { and personnel (perfor- } \\
\text { mance bias) }\end{array}$ & Low risk & $\begin{array}{l}\text { Quote: "The patients were unaware which system had been used on each side } \\
\text { of the mouth, but as the two systems had different modes of application, it } \\
\text { was not possible to blind the operators to the type of system being used" }\end{array}$ \\
\hline
\end{tabular}

Enamel etching for bonding fixed orthodontic braces (Review) 
Murfitt 2006 (Continued)

All outcomes
Comment: we do not consider that lack of blinding will have influenced the outcomes

\begin{tabular}{|c|c|c|}
\hline $\begin{array}{l}\text { Blinding of outcome as- } \\
\text { sessment (detection bias) } \\
\text { All outcomes }\end{array}$ & Low risk & $\begin{array}{l}\text { Comment: no blinding of outcome assessments. However, we do not consider } \\
\text { that lack of blinding will have influenced the outcomes }\end{array}$ \\
\hline $\begin{array}{l}\text { Incomplete outcome data } \\
\text { (attrition bias) } \\
\text { All outcomes }\end{array}$ & Low risk & $\begin{array}{l}\text { Quote: "All patients were observed for the entire } 12 \text {-month period apart from } \\
\text { one 13-year-old male who moved to another city after } 7 \text { months of observa- } \\
\text { tion, during which time no bracket failures occurred" }\end{array}$ \\
\hline $\begin{array}{l}\text { Selective reporting (re- } \\
\text { porting bias) }\end{array}$ & High risk & $\begin{array}{l}\text { Comment: outcomes were reported as stated in the 'Methods' section but we } \\
\text { considered it inappropriate to report at tooth level rather than at participant } \\
\text { level }\end{array}$ \\
\hline Other bias & Low risk & $\begin{array}{l}\text { Comment: we were unable to identify any other apparent sources of bias in the } \\
\text { study }\end{array}$ \\
\hline
\end{tabular}

Noble 2006

\begin{tabular}{l} 
Study design: randomized controlled trial, split-mouth design \\
Time frame: not reported \\
Duration of the study: not reported \\
Stratification: no \\
Sample size calculation: not mentioned \\
\hline
\end{tabular}

Participants

Setting: Dental Branch, University of Texas, Houston, USA

Inclusion criteria: not mentioned

Exclusion criteria: gold, stainless steel or ceramic crowns; extremely large amalgam restorations

Age: 11 to 30 years

Sex: not mentioned

Participant type: not mentioned

Total recruited: 20 participants (371 teeth)

Interventions Group 1: 184 brackets bonded with First Step SEP (Reliance Orthodontic Products)

Group 2: 187 brackets bonded with Transbond Plus SEP (3M Unitek)

\begin{tabular}{ll}
\hline Outcomes & Primary: bond failure rate (6 months) \\
& Secondary: location of failures \\
\hline Notes & Funding: not mentioned \\
& Author contact: none
\end{tabular}

\section{Risk of bias}

\section{Bias}

Authors' judgement Support for judgement

Enamel etching for bonding fixed orthodontic braces (Review) 
Noble 2006 (Continued)

Random sequence genera- Unclear risk Quote: "One experimental quadrant was randomly selected to receive First tion (selection bias) Step self-etching primer along with the conta-lateral quadrant in the opposing arch"

Comment: insufficient information

\begin{tabular}{|c|c|c|}
\hline $\begin{array}{l}\text { Allocation concealment } \\
\text { (selection bias) }\end{array}$ & Unclear risk & $\begin{array}{l}\text { Comment: there is insufficient information in the report to establish whether } \\
\text { or not allocation was properly concealed }\end{array}$ \\
\hline
\end{tabular}

\begin{tabular}{|c|c|c|}
\hline $\begin{array}{l}\text { Blinding of participants } \\
\text { and personnel (perfor- } \\
\text { mance bias) } \\
\text { All outcomes }\end{array}$ & Low risk & $\begin{array}{l}\text { Comment: no blinding of participants and personnel. However, we do not con- } \\
\text { sider that lack of blinding will have influenced the outcomes }\end{array}$ \\
\hline $\begin{array}{l}\text { Blinding of outcome as- } \\
\text { sessment (detection bias) } \\
\text { All outcomes }\end{array}$ & Low risk & $\begin{array}{l}\text { Comment: no blinding of outcome assessments. However, we do not consider } \\
\text { that lack of blinding will have influenced the outcomes }\end{array}$ \\
\hline $\begin{array}{l}\text { Incomplete outcome data } \\
\text { (attrition bias) } \\
\text { All outcomes }\end{array}$ & Low risk & Comment: no participants were reported to have dropped out during the trial \\
\hline $\begin{array}{l}\text { Selective reporting (re- } \\
\text { porting bias) }\end{array}$ & High risk & $\begin{array}{l}\text { Comment: outcomes were reported as stated in the 'Methods' section but we } \\
\text { considered it inappropriate to report at tooth level rather than at participant } \\
\text { level }\end{array}$ \\
\hline Other bias & Low risk & $\begin{array}{l}\text { Comment: we were unable to identify any other apparent sources of bias in the } \\
\text { study }\end{array}$ \\
\hline
\end{tabular}

\section{Paschos 2009}

Study design: randomized controlled trial, split-mouth design
Time frame: not mentioned
Duration of the study: it took 12 months to finish the trial
Stratification: no
Sample size calculation: clearly mentioned

Inclusion criteria: good general health; completely erupted anterior teeth and premolars; mild tooth irregularities; class I molar relationships; no caries and buccal restorations on the teeth to be investigated; healthy periodontal tissues without additional antiplaque regimens; no drugs taken within the last 6 months and during the study

Exclusion criteria: not clearly mentioned

Age: in total 24 participants, range 12 to 15 years; mean 13.12 years, SD $=0.91$

Sex: male 9, female 15

Participant type: class I molar relationships 
Paschos 2009 (Continued)

Group 2: 240 brackets bonded with Clearfil Protect Bond SEP (Kuraray Medical)

Primary outcome: bond failure rate (12 months)
Secondary outcome: the performance of the 2 SEPs regarding the effect on the adjacent enamel:
plaque index (PI), visual rating (VR), and differences of DIAGNOdent values (DD)

Funding: not mentioned
Author contact: further information was requested from the authors but there was no reply

\section{Risk of bias}

\begin{tabular}{lll}
\hline Bias & Authors' judgement & Support for judgement \\
\hline $\begin{array}{l}\text { Random sequence genera- } \\
\text { tion (selection bias) }\end{array}$ & Low risk & $\begin{array}{l}\text { Quote: "brackets.....were bonded on the anterior teeth and the premolars.....in } \\
\text { a randomized split-mouth design. For the random selection, lots were drawn } \\
\text { by an assistant. The application order and the quadrant location were ran- } \\
\text { domly chosen" }\end{array}$ \\
\hline
\end{tabular}

\begin{tabular}{|c|c|c|}
\hline $\begin{array}{l}\text { Allocation concealment } \\
\text { (selection bias) }\end{array}$ & Unclear risk & $\begin{array}{l}\text { Comment: there is insufficient information in the report to establish whether } \\
\text { or not allocation was properly concealed }\end{array}$ \\
\hline
\end{tabular}

\begin{tabular}{ll}
\hline $\begin{array}{l}\text { Blinding of participants } \\
\text { and personnel (perfor- }\end{array}$ & Low risk \\
mance bias) & $\begin{array}{l}\text { Comment: not mentioned. However, we do not consider that lack of blinding } \\
\text { will have influenced the outcomes }\end{array}$ \\
All outcomes &
\end{tabular}

Blinding of outcome as- Low risk sessment (detection bias)

All outcomes
Quote: "the plaque index (PI) was determined by a blinded examiner"

Comment: for the secondary outcomes (PI, VR, and DD), the outcome assessor was blinded and we do not consider that lack of blinding will have influenced the primary outcome

\begin{tabular}{lll}
\hline $\begin{array}{l}\text { Incomplete outcome data } \\
\text { (attrition bias) } \\
\text { All outcomes }\end{array}$ & Low risk & Quote: "Lost to follow-up $(\mathrm{n}=0) "$ \\
\hline $\begin{array}{l}\text { Selective reporting (re- } \\
\text { porting bias) }\end{array}$ & High risk & $\begin{array}{l}\text { Comment: outcomes were reported as stated in the 'Methods' section but we } \\
\text { considered it inappropriate to report at tooth level rather than at participant } \\
\text { level }\end{array}$ \\
\hline Other bias & Low risk & $\begin{array}{l}\text { Comment: we were unable to identify any other apparent sources of bias in the } \\
\text { study }\end{array}$ \\
\hline
\end{tabular}

$\mathrm{SD}=$ standard deviation; SEP = self etching primer.

Characteristics of excluded studies [ordered by study ID]

\begin{tabular}{ll}
\hline Study & Reason for exclusion \\
\hline Amasyali 2011 & $\begin{array}{l}\text { Did not report any orthodontic outcomes. Not clear if an RCT (participants randomly selected but } \\
\text { no mention of random allocation and study not described as an RCT) }\end{array}$ \\
\hline Artun 1984 & Probably not an RCT (randomization not mentioned) \\
\hline
\end{tabular}




\begin{tabular}{ll}
\hline Study & Reason for exclusion \\
\hline Cal-Neto 2005 & $\begin{array}{l}\text { Unable to confirm if the randomization procedure meets our inclusion criteria (see Types of stud- } \\
\text { ies) }\end{array}$ \\
\hline dos Santos 2006 & Randomized to alternate teeth (see Types of studies) \\
\hline Kinch 1988 & "sequentially assigned" \\
\hline LeCrone 2005 & Probably not an RCT (randomization not mentioned) \\
\hline Miles 2008 & Probably not an RCT (randomization not mentioned) \\
\hline Pandis 2005 & From correspondence with author: "not randomized" \\
\hline Pandis 2006 & From correspondence with author: "not randomized" \\
\hline Reis 2008 & Randomized to alternate teeth (see Types of studies) \\
\hline Roberts-Harry 1992 & Probably not an RCT (randomization not mentioned) \\
\hline Sadowsky 1990 & Not randomly allocated to first quadrant (see Types of studies) \\
\hline
\end{tabular}

$\mathrm{RCT}=$ randomized controlled trial.

\section{DATA AND ANALYSES}

Comparison 1. Self etching primers versus conventional etchants

\begin{tabular}{lllll}
\hline Outcome or subgroup title & No. of studies & $\begin{array}{l}\text { No. of partici- } \\
\text { pants }\end{array}$ & Statistical method & Effect size \\
\hline $\begin{array}{l}1 \text { Bond failure rate }(5 \text { to } 37 \\
\text { months) }\end{array}$ & 5 & 348 & Risk Ratio (Random, 95\% Cl) & $1.14[0.75,1.73]$ \\
\hline 1.1 Split-mouth studies & 3 & 254 & Risk Ratio (Random, 95\% Cl) & $1.09[0.36,3.25]$ \\
\hline 1.2 Parallel studies & 2 & 94 & Risk Ratio (Random, 95\% Cl) & $1.14[0.74,1.76]$ \\
\hline
\end{tabular}

\section{Analysis 1.1. Comparison 1 Self etching primers versus conventional} etchants, Outcome 1 Bond failure rate (5 to 37 months).

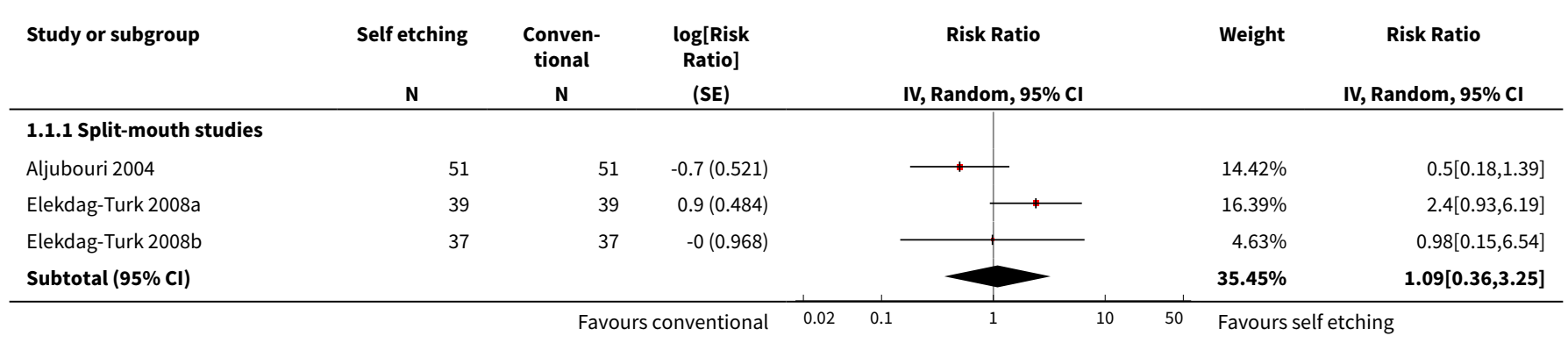




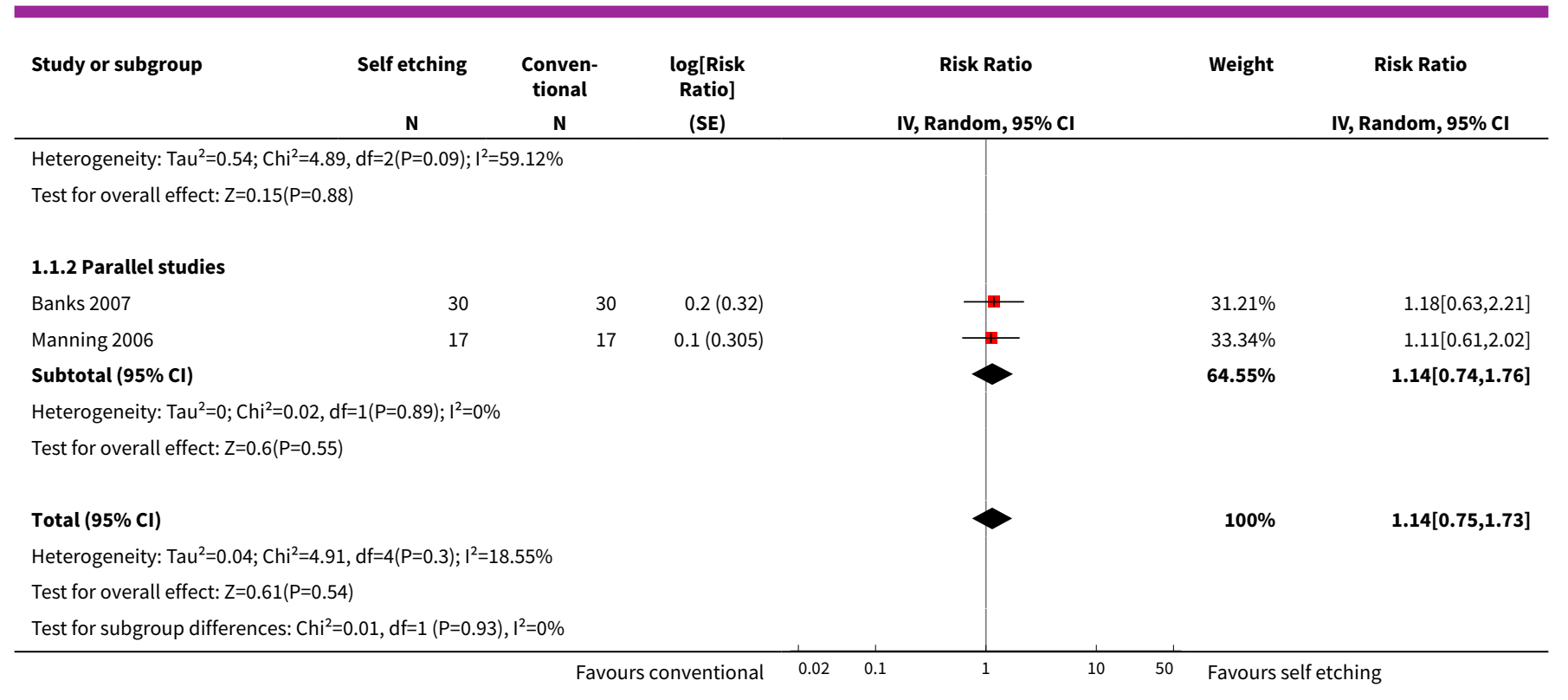

\section{ADDITIONAL TABLES}

Table 1. Raw data for comparison 1.1

\begin{tabular}{llllll}
\hline & SEP & SEP & Conventional & Conventional & Total \\
no failure & $\geq 1$ failure & no failure & 1 failure \\
\hline Aljubouri 2004 & 46 & 5 & 41 & 10 & 102 \\
\hline Elekdag-Turk 2008a & 27 & 12 & 34 & 2 & 78 \\
\hline Elekdag-Turk 2008b & 35 & 2 & 35 & 74 \\
\hline Banks 2007 & 17 & 13 & 19 & 90 \\
\hline Manning 2006 & 7 & 10 & 8 & 37 \\
\hline Total & 132 & 42 & 137 & 34 \\
\hline
\end{tabular}

The actual total number of participants is 221 , rather than 348 , as the top three split-mouth studies included the participants in both intervention groups.

$\mathrm{SEP}=$ self etching primer.

Table 2. Study data not included in comparison 1.1 meta-analysis

\begin{tabular}{lll}
\hline & Comparison & Results for bond failure rate (analyzed at tooth level) at $\mathbf{6}$ to $\mathbf{1 2}$ months \\
\hline Asgari 2002 & $\begin{array}{l}\text { Transbond Plus SEP } \\
\text { versus conventional }\end{array}$ & $\begin{array}{l}\text { "The ' } p \text { ' value of .037 indicated that the bond failure rate using Transbond Plus } \\
\text { Self Etching Primer was significantly less than the bond failure rate in those } \\
\text { quadrants where a } 37 \% \text { phosphoric acid etchant was used" }\end{array}$ \\
\hline Cal-Neto 2009 & $\begin{array}{l}\text { Transbond Plus SEP } \\
\text { versus conventional }\end{array}$ & $\begin{array}{l}\text { "There was no significant difference in terms of bracket failure risk over the } 12 \\
\text { months between groups... } \mathrm{P}=0.311) "\end{array}$ \\
\hline
\end{tabular}


Table 2. Study data not included in comparison 1.1 meta-analysis (Continued)

\begin{tabular}{lll} 
House 2006 & $\begin{array}{l}\text { Ideal } 1 \text { SEP versus con- } \\
\text { ventional }\end{array}$ & $\begin{array}{l}\text { Odds ratio at } 12 \text { months }=15.1 \text { (95\% confidence interval } 7.7 \text { to } 29.3) \text { for fail- } \\
\text { ure of SEP relative to conventional. Recruitment was stopped early due to high } \\
\text { failure rate of SEP group }\end{array}$ \\
\hline Ireland 2003 & $\begin{array}{l}\text { Transbond Plus SEP } \\
\text { versus conventional }\end{array}$ & $\begin{array}{l}\text { "The difference between the failure proportions was }-0.06 \text { with an associat- } \\
\text { ed } 95 \% \text { confidence interval of }-0.121 \text { to } 0.001 \text {. This study produced weak evi- } \\
\text { dence to suggest that bond failures with a self-etching primer will be higher } \\
\text { than those with conventional etching and priming" }\end{array}$ \\
\hline Murfitt 2006 & $\begin{array}{l}\text { Transbond Plus SEP } \\
\text { versus conventional }\end{array}$ & $\begin{array}{l}\text { "Transbond Plus SEP was found to have a significantly higher failure rate than } \\
\text { the conventional } 37 \text { per cent phosphoric acid and primer }(\mathrm{P}=0.001) "\end{array}$ \\
\hline
\end{tabular}

SEP $=$ self etching primer.

\section{APPENDICES}

\section{Appendix 1. Cochrane Oral Health's Trials Register search strategy}

(orthodontic ${ }^{\star}$ AND (brace* OR bracket* OR "fixed appliance*" OR "fixed device*") AND (etch* OR self-etch* OR o-phosphoric OR "maleic acid" OR "polyacrylic acid"))

\section{Appendix 2. Cochrane Central Register of Controlled Trials (CENTRAL) search strategy}

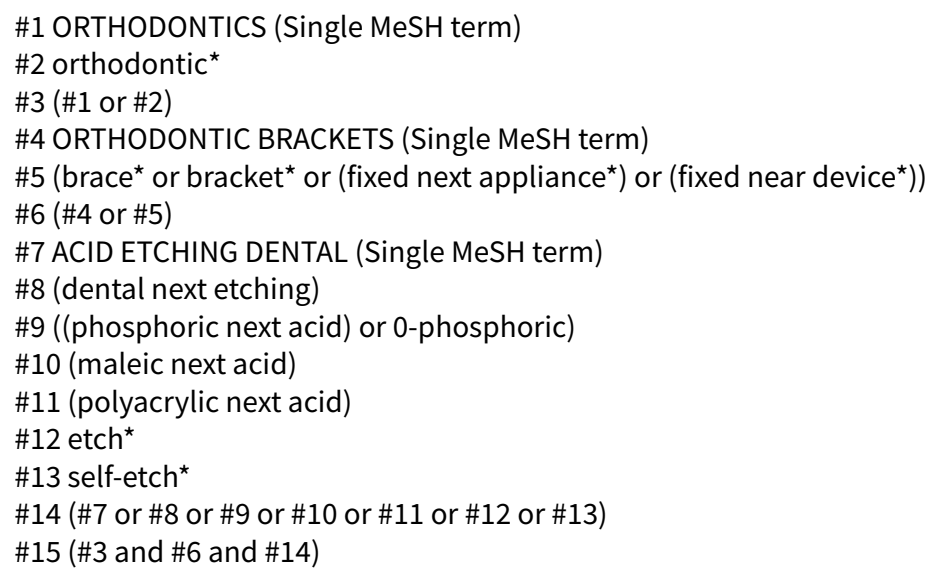

\section{Appendix 3. MEDLINE via OVID search strategy}

\section{ORTHODONTICS/}

2. orthodontic\$.mp.

3. or/1-2

4. ORTHODONTIC BRACKETS/

5. (brace\$ or bracket\$ or (fixed adj appliance\$) or (fixed adj3 device\$)).mp.

6. or/4-5

7. ACID ETCHING DENTAL/

8. (dental adj etching).mp.

9. ((phosphoric adj acid) or o-phosphoric).mp.

10. (maleic adj acid).mp.

11. (polyacrylic adj acid).mp.

12. etch\$.mp.

The above subject search was linked to the Cochrane Highly Sensitive Search Strategy for identifying randomized trials in MEDLINE: sensitivity maximising version (2008 revision) as referenced in Chapter 6.4.11.1 and detailed in Box 6.4.c of theCochrane Handbook for Systematic Reviews of Interventions, Version 5.1.0 (updated March 2011).

1. randomized controlled trial.pt. 
2. controlled clinical trial.pt.

3. randomized.ab.

4. placebo.ab.

5. drug therapy.fs.

6. randomly.ab.

7. trial.ab.

8. groups.ab.

9. or/1-8

10. exp animals/ not humans.sh.

11.9 not 10

\section{Appendix 4. EMBASE via OVID search strategy}

1. Orthodontics/

2. orthodontic\$.mp.

3. or $/ 1-2$

4. Orthodontic brackets/

5. (brace\$ or bracket\$ or (fixed adj appliance\$) or (fixed adj3 device\$)).mp.

6. or/4-5

7. Acid Etching, Dental/

8. (dental adj etching).mp.

9. ((phosphoric adj acid) or o-phosphoric).mp.

10. (maleic adj acid).mp.

11. (polyacrylic adj acid).mp.

12. etch\$.mp.

13. self-etch\$.mp.

14. or $/ 7-13$

15. 3 and 6 and 14

The above subject search was linked to the Cochrane Oral Health Group filter for EMBASE via OVID:

1. random\$.ti,ab.

2. factorial\$.ti,ab.

3. (crossover\$ or cross over\$ or cross-over\$).ti,ab.

4. placebo\$.ti,ab.

5. (doubl\$ adj blind\$).ti,ab.

6. (singl\$ adj blind\$).ti,ab.

7. assign\$.ti,ab.

8. allocat\$.ti,ab.

9. volunteer $\$$.ti,ab.

10. CROSSOVER PROCEDURE.sh.

11. DOUBLE-BLIND PROCEDURE.sh.

12. RANDOMIZED CONTROLLED TRIAL.sh.

13. SINGLE BLIND PROCEDURE.sh.

14. or/1-13

15. ANIMAL/ or NONHUMAN/ or ANIMAL EXPERIMENT/

16. HUMAN/

17. 16 and 15

18. 15 not 17

19. 14 not 18

\section{Appendix 5. WHO International Clinical Trials Registry Platform search strategy}

orthodontic*AND etch*

brace* AND etch $^{\star}$

bracket $^{*}$ AND etch*

appliance* AND etch*

device ${ }^{\star}$ AND etch ${ }^{\star}$

\section{Appendix 6. ClinicalTrials.gov search strategy}

orthodontic* AND etch*

brace $^{\star}$ AND etch*

bracket $^{\star}$ AND etch ${ }^{\star}$ 
appliance* AND etch *

device $^{\star}$ AND etch*

WHAT'S NEW

\begin{tabular}{lll}
\hline Date & Event & Description \\
\hline 24 May 2018 & Review declared as stable & This review has had low usage and is not a priority for updating. \\
\hline
\end{tabular}

\section{HISTORY}

Protocol first published: Issue 4, 2005

Review first published: Issue 11, 2013

\begin{tabular}{lll}
\hline Date & Event & Description \\
\hline 5 September 2008 & Amended & Converted to new review format. \\
\hline
\end{tabular}

\section{CONTRIBUTIONS OF AUTHORS}

- Haikun $\mathrm{Hu}(\mathrm{HKH})$ and Qingsong Ye (QSY) conceived the review and they proposed this clinical question and registered the title with Cochrane Oral Health.

- HKH and QSY designed the review.

- HKH, QSY and Fan Li (FL) carried out data collection for the review.

- QSY, HKH and FL designed search strategies.

- $\mathrm{HKH}, \mathrm{QSY}$ and FL undertook searches.

- HKH and Chunjie Li (CJL) screened search results.

- HKH and Philip Riley (PR) organized retrieval of papers.

- $\mathrm{HKH}$ and CJL screened retrieved papers against eligibility criteria.

- HKH and CJL appraised quality of papers.

- HKH and CJL extracted data from papers.

- HKH and CJL wrote to authors of papers for additional information.

- Shujuan Zou (SJZ) and Jianwei Chen (JWC) provided additional data about papers.

- CJL, JWC and Jianfeng Sun (JFS) carried out data management for the review.

- CJL and JFS entered data into RevMan.

- HKH, QSY and CJL carried out analysis of data.

- HKH, PR and CJL carried out interpretation of data.

- QSY and PR provided a methodological perspective.

- SJZ, QSY and Qiang Xu (QX) provided a clinical perspective.

- HKH, PR, QSY and CJL wrote the review.

- QSY, SJZ and Andrew Sandham (AS) provided general advice on the review.

- QSY, PR, QX and AS revised this review.

\section{DECLARATIONSOF INTEREST}

None of the review authors have any financial interests that would represent a conflict of interest.

\section{SOURCES OF SUPPORT}

\section{Internal sources}

- Wenzhou Medical University, China. 
- Department of Orthodontics, James Cook University, Cairns, Australia.

- West China College of Stomatology, Sichuan University, China.

- Chinese EBM/Cochrane Center, China.

- Taizhou Hospital, Zhejiang, China.

- Manchester Academic Health Sciences Centre (MAHSC), UK.

Cochrane Oral Health is supported by the Manchester Academic Health Sciences Centre (MAHSC) and the NIHR Manchester Biomedical Research Centre

- The University of Manchester, UK.

\section{External sources}

- Cochrane Oral Health Global Alliance, Other.

The production of Cochrane Oral Health reviews has been supported financially by our Global Alliance since 2011 (oralhealth.cochrane.org/partnerships-alliances). Contributors over the past year have been the American Association of Public Health Dentistry, USA; AS-Akademie, Germany; the British Association for the Study of Community Dentistry, UK; the British Society of Paediatric Dentistry, UK; the Canadian Dental Hygienists Association, Canada; the Centre for Dental Education and Research at All India Institute of Medical Sciences, India; the National Center for Dental Hygiene Research \& Practice, USA; New York University College of Dentistry, USA; NHS Education for Scotland, UK; and the Swiss Society for Endodontology, Switzerland.

- National Institute for Health Research (NIHR), UK.

This project was supported by the NIHR, via Cochrane Infrastructure funding to Cochrane Oral Health. The views and opinions expressed herein are those of the review authors and do not necessarily reflect those of the Systematic Reviews Programme, the NIHR, the NHS or the Department of Health

\section{DIFFERENCES BETWEEN PROTOCOLANDREVIEW}

1. In the section Types of studies, we limited the criteria to only randomized controlled trials (RCTs) in order to improve the quality of this systematic review.

2. The WHO International Clinical Trials Registry Platform and CBM were searched electronically, which was not proposed in the protocol.

3. We added an exclusion criterion for studies that compared different dental etchants or different etching techniques but did not report any orthodontic outcomes.

\section{NOTES}

No update planned. This review has had low usage and is not a priority for updating.

\section{INDEX TERMS}

\section{Medical Subject Headings (MeSH)}

${ }^{\star}$ Orthodontic Brackets; Acid Etching, Dental [adverse effects] [ ${ }^{\star}$ methods]; Cementation [adverse effects] [ ${ }^{\star}$ methods]; Randomized Controlled Trials as Topic; Tooth Demineralization [chemically induced]

\section{MeSH check words}

Humans 